\title{
"RHEUMATOID ARTHRITIS" WITH NEGATIVE SEROLOGICAL REACTION
}

\author{
BY \\ A. ST. J. DIXON \\ Postgraduate Medical School, London
}

This paper describes a follow-up study of inpatients with severe active rheumatoid polyarthritis, in whom the sensitized sheep cell agglutination test (S.C.A.T., Ball, 1950) was found to be negative.

\section{Patients}

The patients reviewed in this study comprise all those treated as in-patients in the rheumatism beds of the Manchester Royal Infirmary during the period 1948 to 1956 inclusive, who were sero-negative, but in whom, during their first admission, no diagnosis other than rheumatoid arthritis or polyarthritis of undetermined type could be made by the accepted criteria (Ropes, Bennett, Cobb, Jacox, and Jessar, 1956). An erythrocyte sedimentation rate of over $20 \mathrm{~mm}$./hr (Westergren) was also required as a criterion of disease activity. 63 patients conformed to this definition and these were selected for followup. This number represents some 6 per cent. of all the patients admitted to the rheumatism beds during these years. While the patients were in hospital the S.C.A.T. was done weekly; some tests were also done at subsequent out-patient attendances, but in all cases the test was repeated at the follow-up examination.

\section{Serological Criteria}

For this study it was desirable to eliminate borderline results in the test so that a negative test was defined as one in which no agglutination was observed after incubation for $18 \mathrm{hrs}$ with serum dilutions greater than $1: 8$. This criterion for a negative test is more strict than that described in previous publications from this Centre, in which agglutination with a titre of $1: 32$ is accepted as a minimal positive result (Kellgren and Ball, 1959). Great care has been taken to maintain standard sensitivity of the test over the years, and all new batches of reagents are adjusted to give standard results with arbitrary standard sera. Control sera of known titre are tested with each batch of unknown sera, and the whole batch is retested or rejected if the controls are unsatisfactory. Control sera are stable for at least a year. Thus changes in the S.C.A.T. observed at follow-up may be regarded as real and not "technical".

This study group of patients was tested frequently. So that the results of all available tests could be taken into account, those patients in whom not more than one borderline titre of $1: 16$ was found amongst at least four negative tests within any 6 months' period were included as sero-negative and were not excluded from the follow-up series, but if more than 25 per cent. of the readings during any 6 months were $1: 16$ or more, the case was excluded from follow-up. In the remainder of this paper, the convention of reciprocal titre will be observed. Thus a S.C.A.T. of less than 4 , 4 , or 8 is negative, of 32,64 , etc., positive, and of 16 "doubtful positive".

\section{Diagnostic Criteria and Predictability of the S.C.A.T.}

In typical, sero-positive nodular rheumatoid arthritis, the disease may start in many ways, and the pattern of joint involvement at onset may differ from that seen later. Nevertheless, it has been shown that in hospital in-patients with polyarthritis the results of the S.C.A.T. can be predicted from the clinical and radiological features of the case with considerable accuracy (Kellgren and Ball, 1959) and as a result of this the clinical features of fullydeveloped sero-positive rheumatoid arthritis have become more clearly defined. Typical rheumatoid arthritis showed symmetrical peripheral polyarthritis, including (as a minimum) involvement of both wrists, the second and third metacarpophalangeal joints of both hands, and the lateral metatarsophalangeal joints in the feet. In the more 
developed case, of course, this extended to involve all the small joints of the hands and feet as well as the larger limb joints. Atypical arthritis was diagnosed when mainly central, large joint, or asymmetrical involvement was seen. In practice the distinction was seldom difficult. Radiological evidence of subchondral and juxta-articular erosions was helpful in assessing the extent and distribution of joint involvement.

\section{Follow-up Procedure}

All patients were recalled for a review of the history and a fuller examination. Nodules were sought over bony prominences, under the heels, and in the finger flexor tendons. Only moderate or large flexor tendon nodules were considered significant. Blood was taken for S.C.A.T., E.S.R. (Westergren), Hb per cent., and serum urate estimations (Brown, 1945). Further radiographs were taken where indicated and all previous films were reviewed.

\section{Results}

Tables I and II show that the follow-up was reasonably complete and that nearly half of the patients were observed for 5 years or more.

TABLE I

COMPLETENESS OF FOLLOW-UP

\begin{tabular}{|c|c|c|c|c|c|c|}
\hline \multicolumn{5}{|c|}{ Follow-up } & No. & Per cent. \\
\hline \multicolumn{5}{|c|}{ Total patients chosen for follow-up .. } & 63 & 100 \\
\hline \multicolumn{5}{|c|}{ Seen again as out-patients or in-patients } & 50 & 79 \\
\hline \multicolumn{2}{|c|}{ Died in interval $\quad \ldots$} & $\cdots$ & $\cdots$ & $\cdots$ & 6 & 10 \\
\hline \multicolumn{2}{|c|}{ Follow-up by letter only } & $\cdots$ & $\cdots$ & $\cdots$ & 5 & 8 \\
\hline \multirow{2}{*}{$\begin{array}{l}\text { Failed } \\
\text { follow-up }\end{array}$} & Not trace & $\cdots$ & $\cdots$ & $1)$ & \multirow{2}{*}{2} & \multirow{2}{*}{3} \\
\hline & \multicolumn{4}{|c|}{ Traced but did not reply 1 ) } & & \\
\hline
\end{tabular}

TABLE II

INTERVAL BETWEEN HOSPITAL ADMISSION AND FOLLOW-UP OR DEATH

\begin{tabular}{lcc|cccccccccc|c}
\hline Interval (yrs) &.. &. & 10 & 9 & 8 & 7 & 6 & 5 & 4 & 3 & 2 & 1 & Total \\
\hline No. of Patients .. &. & 1 & 5 & 2 & 8 & 6 & 7 & 5 & 6 & 14 & 7 & 61 \\
\hline
\end{tabular}

The findings at follow-up are summarized in Table III. Twelve patients became sero-positive. This includes all of the six patients who developed persistent subcutaneous nodules. In ten of this group the arthritis was typical in distribution, and in these cases either flexor tendon nodules and/or subcutaneous nodules were present at follow-up.

TABLE III

CLINICAL FINDINGS IN RELATION TO S.C.A.T., AS DETERMINED AT FOLLOW-UP OR DEATH

\begin{tabular}{|c|c|c|c|c|}
\hline \multirow[b]{2}{*}{ Clinical Findings } & \multicolumn{4}{|c|}{ S.C.A.T. Titres } \\
\hline & $\begin{array}{c}1: 32 \\
\text { or } \\
\text { More }\end{array}$ & $1: 16$ & $\begin{array}{l}1: 8 \text { or } \\
\text { Less }\end{array}$ & Total \\
\hline $\begin{array}{l}\text { Typical Rheumatoid } \\
\text { Arthritis }\end{array}$ & 9 & 1 & $\left.\begin{array}{l}\text { Alive 21 } \\
\text { Dead 3 }\end{array}\right\} 24$ & $\left.\begin{array}{l}\text { Alive } 31 \\
\text { Dead } 3\end{array}\right\} 34$ \\
\hline $\begin{array}{l}\text { Atypical Rheumatoid } \\
\text { Arthritis (All Alive) }\end{array}$ & 1 & 1 & 9 & 11 \\
\hline Other Arthritides & 0 & 0 & $\left.\begin{array}{ll}\text { Alive } & 8 \\
\text { Dead } & 3\end{array}\right\} 11$ & $\left.\begin{array}{ll}\text { Alive } & 8 \\
\text { Dead } & 3\end{array}\right\} 11$ \\
\hline Total & 10 & 2 & 44 & 56 \\
\hline
\end{tabular}

The duration from the onset of disease to the 을 development of sero-positivity can be approximated $\vec{c}$ from Table IV, which shows that this process may $\mathcal{D}_{\mathcal{D}}$ take at least 15 years and possibly even longer in $\frac{\mathbb{P}}{\mathbb{P}}$ some cases.

TABLE IV

DURATION OF ARTHRITIS BEFORE S.C.A.T. CONVERSION (YRS)

\begin{tabular}{|c|c|c|c|}
\hline Duration from & nset of Arthritis & $\begin{array}{c}\text { To Last } \\
\text { Recorded } \\
\text { Negative } \\
\text { S.C.A.T. }\end{array}$ & $\begin{array}{c}\text { To First } \\
\text { Recorded } \\
\text { Positive } \\
\text { S.C.A.T. }\end{array}$ \\
\hline $\begin{array}{l}\text { (A) Typical } \\
\text { Arthritis }\end{array}$ & $\begin{array}{l}\text { N.W. } \\
\text { E.C. (Case 28) } \\
\text { M.H. (Case 26) } \\
\text { U.W. (Case 2) } \\
\text { N.W. (Case 1) } \\
\text { D.S. (Case 17) } \\
\text { J.R. (C. } \\
\text { M.R. } \\
\text { I.L. (Case 4) } \\
\text { E.H. (C) }\end{array}$ & $\begin{array}{r}3 \\
2 \\
9 \\
15 \\
10 \\
2 \\
6 \\
2 \\
1 \\
7\end{array}$ & $\begin{array}{l}5(1: 16) \\
6 \\
15 \\
23 \\
12 \\
8 \\
13 \\
5 \\
2 \\
14\end{array}$ \\
\hline $\begin{array}{l}\text { (B) Atypical } \\
\text { Arthritis }\end{array}$ & $\begin{array}{l}\text { K.D. (Case 3) } \\
\text { J.H. }\end{array}$ & $\begin{array}{r}13 \\
4\end{array}$ & $\frac{14(1: 16)}{6}$ \\
\hline
\end{tabular}

In only one patient who eventually developed typical arthritis and a positive serology was the응 arthritis observed to be atypical for a major proportion of the course of the disease.

Case 1, a man aged 55, had pain in the left shoulder in $\bigcirc$ 1949. Both knees and both wrists were involved later N that year, and the neck and metacarpophalangeal joint $\stackrel{\circ}{N}$ of one thumb the following year. He was seen regularly $\omega$ in hospital, but a typical distribution of involvement of the metacarpophalangeal and proximal interphalangeake joints was not observed until 5 years after onset. Typical subcutaneous nodules appeared about the same time. His subsequent course showed steady deterioration. 


\section{Another patient in this group is of interest.}

Case 2, a woman aged 34, had developed arthritis in the right shoulder, and this had spread to involve all the large limb joints except the hips. Ten courses of gold treatment were given with diminishing success over the next 10 years. After 9 years her fingers became involved. After 10 years nodules were removed from both elbows, and 5 years later she attended hospital with typical active advanced rheumatoid arthritis (E.S.R. $82 \mathrm{~mm}$./hr) and established deformities of the hands and feet. Her thumbs were disorganized at the interphalangeal joints, and these joints were surgically arthrodesed. Histological examination (Dr. J. Ball) of the tissue removed at surgical arthrodesis of the thumbs showed dense fibrous tissue containing an old necrobiotic focus and areas of active inflammatory proliferation and infiltration. Three estimations of the S.C.A.T. were $4,<4$, and $<4$ respectively. 8 years later, at follow-up, when she was aged 66, further subcutaneous nodules had appeared, and her appearance was that of "arthritis mutilans".

The S.C.A.T. was then positive (128).

One patient developed a S.C.A.T. of 16 (doubtful positive) whilst her arthritis was considered to be atypical.

Case 3, a woman aged 38, began to have intermittent hydrarthrosis of the left knee when aged 24 . The attacks were regular but not disabling until the age of 33 , when both knees began to swell intermittently, with residual permanent swelling from the age of 36 . Persistent arthritis of the right wrist started at age 36 and of the right shoulder at age 37. Small heel nodules were noted on examination at age 38. Five estimations of the S.C.A.T. at age 37 were negative $(8,8,4,8,8)$, but at follow-up one year later the titre had risen to 16 .

Comment.-The majority of those who became sero-positive showed a typical arthritis from an early phase of the disease, but an interval of up to 15 years might elapse before serological conversion was observed to occur, and this is relevant to the evaluation of the remaining patients in this study, in the majority of whom sero-conversion did not occur, and who had not been followed for as long as this. In Case 2, sero-negativity for many years was compatible with presence in the body of extensive synovial disease, histologically similar to, if not indistinguishable from, the appearance of subcutaneous nodules.

Sero-negative Group with Typical Distribution of Arthritis.-Of the 24 patients in this group, only one had shown transient subcutaneous nodules, and eight (including three of those who had died) showed no nodules of any sort, but there remained twelve who were noted to have significant flexor tendon nodules. In ten of these twelve, radiographs revealed evidence of articular bone erosion. Comparison of these 24 patients with the ten who had typical arthritis and who became sero-positive revealed no other notable differences, either in course or outcome. Both mild and severe endresults were seen. In one patient inflammatory polyarthritis was very severe indeed and was the cause of death.

Case 4, a woman aged 50, injured her right index finger, which became swollen, stiff, and painful. After 6 months, swelling spread to her knees and most other joints. There was much constitutional illness and loss of weight. When seen at the age of 52 she was wasted and ill, with enlargement of the lymph nodes. All joints were involved, but the smaller peripheral joints were especially swollen, tender, limited, and in many cases subluxed. There was slight fever (to $99.6^{\circ} \mathrm{F}$.), anaemia (haemoglobin 50 to 68 per cent.), and reversal of the serum protein ratio (albumin $2.6 \mathrm{~g}$. per cent.; globulin $3.7 \mathrm{~g}$. per cent.). A chest radiograph was normal. All treatment was unsuccessful.

At the age of 54 the patient died, and at autopsy (Dr. Ball) showed gross deforming rheumatoid arthritis; the histology was that of an extensive erosive arthropathy without ligamentous calcification, affecting especially the small joints, although all joints (including the sacro-iliac, lumbar interfacetal, and sternoclavicular) were involved. The condition was entirely compatible with rheumatoid arthritis. Five estimations of the S.C.A.T. had all been negative $(4$ or $<4)$. Pulmonary tuberculosis was also found, but was histologically a terminal infection, an opinion supported by a shortly previous normal chest $x$ ray.

\section{Other patients in this group have fared better.}

Case 5, a woman aged 58, developed general illness, loss of weight, and swelling and stiffness of the hands. By age 59 she had symmetrical involvement of the proximal interphalangeal joints and metacarpophalangeal joints, especially the first and second on each hand, and there was involvement of wrists, elbows, shoulders, neck, knees, ankles, and feet, with pain and limitation of movement. Large crepitant flexor tendon nodules were present. The erythrocyte sedimentation rate was $43 \mathrm{~mm}$./hr and the serum albumin and globulin concentrations were 3.8 and $4.4 \mathrm{~g}$. per cent. At follow-up the following year she had experienced an excellent recovery. There was some residual swelling, deformity, and weakness of the fingers and toes, and the erythrocyte sedimentation rate had fallen to $11 \mathrm{~mm}$./hr. Three estimations of her S.C.A.T. were all negative $(<4)$. 
Only one patient in the group was considered to have made a complete recovery.

Case 6, a man aged 47, had arthritis characterized by an episodic course with complete remissions. Many of the episodes had followed upper respiratory infections and he gave a history of previous rheumatic fever. His first admission to hospital was for a more prolonged arthritis which lasted about a year and started 3 weeks after a sore throat, severe enough to cause dysphagia and cervical lymphadenitis. Small transient nodules were noted on the elbows and he showed a peripheral symmetrical arthritis, mainly affecting the wrists, metacarpophalangeal joints, knees, and feet. Three further attacks of polyarthritis with recovery occurred in the next 4 years.

The distribution of arthritis was considered typical of rheumatoid arthritis and there was never cardiac involvement; nevertheless, the diagnosis of recurrent rheumatic fever would have been equally appropriate.

Some 30 per cent. of patients with rheumatic fever do not develop carditis (and adults are said to be less prone to this complication than children). One further patient in this group is of interest:

Case 7, a woman aged 55, developed in addition to her polyarthritis a myopathy with dysphagia, weakness of voice and limbs, difficulty in coughing, regurgitation of food, and creatinuria of $250 \mathrm{mg}$. $24 \mathrm{hrs}$. A muscle biopsy showed only thinning of the fibres and no vascular lesions. With corticotrophin or prednisolone her symptoms from both arthritis and myopathy improved, her creatinuria disappeared, and the erythrocyte sedimentation rate fell from 65 to $5 \mathrm{~mm}$./hr. 9 years after the start of the illness her arthritis was quiescent but she still experienced marked weakness if an attempt were made to withdraw steroids. The erythrocyte sedimentation rate remained elevated at $47 \mathrm{~mm}$./ hr, and radiographs showed progression of the erosive changes in articular bone. Significant flexor tendon nodules, which had been noted when she was first seen, were still present. Four estimations of the S.C.A.T. had all been negative.

Sero-Negative Group with Atypical Distribution of Arthritis.-Nine patients had an atypical distribution of arthritis, no nodules of any sort, and a persistently negative S.C.A.T. Thus they were both clinically and serologically atypical of rheumatoid arthritis, although no other diagnosis could be made on commonly accepted criteria. They will be described in more detail. They were not an homogeneous group.

Case 8, a woman aged 43, had become pale and ill when aged 38. The next year there was swelling and pain in the proximal and distal interphalangeal joints of the third right finger, and 3 months later she took to her bed. She lost weight and arthritis spread to all limb joints and the spine. A course of gold injections was given but was stopped because of albuminuria. Shø was admitted to hospital in January, 1954, with severê? active polyarthritis, and much inflammation and pain: in all joints, but mainly in the larger joints and hips $\stackrel{?}{+}$ The erythrocyte sedimentation rate rose to $99 \mathrm{~mm}$./h? and the haemoglobin fell to 76 per cent. A furthe attempt to give gold therapy led to dermatitis and she wassp. discharged only moderately improved, to be re-admitted in February, 1957. During the interval she had beeng followed in the out-patient department. Her arthritis had remained active and the erythrocyte sedimentatiob rate had risen to over $100 \mathrm{~mm}$./hr. For most of the time she had been mainly bedfast. A curious symptona was that of a "burning" sensation which she had experis enced in both large and small joints, without othe evidence of peripheral neuropathy. It was particularly troublesome at night, and she had to leave her limbs uncovered by the bedclothes in order to obtain relief This symptom stopped when prednisolone therapy was started. Her lymph nodes were enlarged and there was clinical involvement of all joints, especially marked in the hips. The haemoglobin was normal at 102 per cent despite her chronic illness. Numerous other investigad tions were normal or non-contributory. Radiographs showed considerable progression of the hip lesion sinc\& 1954 , with narrowing of the joint spaces from cartilago destruction and proliferation of bone at the joint margins. There were no erosions of articular bone. Similagl $\overrightarrow{60}$ in the wrists, ankles, and knees, there was osteoporsig with cartilage but not bone destruction and there Has bony proliferation at the joint margins. Apart foron porosis the radiographs of the fingers and toes wers normal.

She failed to do well until routine treatment was supplemented by prednisolone $20 \mathrm{mg}$./day, after which she was able to get up and resume limited housework at the follow-up examination in 1957, she had some residual flexion contractures of the hips and the erythro cyte sedimentation rate was $60 \mathrm{~mm}$./ $/ \mathrm{hr}$. The haem globin was 98 per cent. Five estimations of the S.C.A.T. had all been negative.

Comment.-The unusual features this patien presented were mainly the large-joint distribution of the arthritis, the absence of articular bone erosion the primary bone proliferation around the joints the severe and prolonged constitutional illness without anaemia, and the persistently negatis S.C.A.T.

Case 9, a woman aged 53, had noted the sudden onseo of acute pain and swelling in the right big toe in 1952 The part was bluish red and the pain was described $\alpha_{S}$ "burning". Later the left toe was similarly affected and the following year she suddenly developed inflammation in both wrists. The right knee swelled insidiously and developed a flexion contracture. On each of threse admissions to another hospital her illness was diagnosed 
as gout, but the serum uric acid was never raised and colchicine did not help her. At age 56 she developed a tense effusion in the right knee, swelling of the bursae under the Achilles tendon insertions, minor pain in the bases of the lateral toes, the left ankle, and both wrists, and some swelling and pain in the second right proximal interphalangeal joint. The conditions responded to rest followed by slow rehabilitation. The erythrocyte sedimentation rate fell from $55 \mathrm{~mm}$./hr to normal levels and joint function became almost normal. The left ankle became painful again but responded to local injections and hydrocortisone, and she was able to do all her housework and to travel several miles each day in order to look after her invalid mother. There was no family history of gout, arthritis, or psoriasis, and nothing to suggest the non-articular features of Reiter's syndrome. Four estimations of the serum uric acid were $3.6 \mathrm{mg}$. per cent. or less and the S.C.A.T. was negative on four occasions.

Comment.-The atypical features of this patient's illness were the initial gout-like episodes of joint involvement. the subsequent distribution involving mainly the large joints, and the excellent recovery. Her disease fits in with a pattern of involvement and evolution which we have observed in association with some cases of psoriasis, of which, however, there was no other evidence.

The following two cases showed marked constitutional disease associated with a severe central polyarthritis which progressed to complete recovery.

Case 10, an unmarried children's nurse aged 58, was well until she began to lose weight, $28 \mathrm{lb} .(12 \cdot 7 \mathrm{~kg}$.), and felt unwell and easily fatigued. The following year she noted increasing morning stiffness in both legs and there was aching pain referred to the region of the vagina. Stiffness and weakness increased until finally she was unable to get up from a chair unaided. She became ill and feverish, and took to her bed. She was admitted to another hospital where little could be found wrong, except that she was anaemic (haemoglobin 76 per cent., falling to 58 per cent.), had a mild fever (to $100^{\circ} \mathrm{F}$. daily) and a high erythrocyte sedimentation rate (38 rising to $65 \mathrm{~mm}$./hr). A retained root of a tooth was removed. 4 days later the left knee swelled for the first time. Her general condition continued to worsen, and there was more pain and stiffness in the shoulders, back and legs. Subsequently she was found to have urine chronically infected with $E$. coli which did not respond to appropriate antibiotics. The right knee swelled painfully and she was transferred to the Manchester Royal Infirmary for further care. Her brother had died at the age of 50 after being crippled for many years with spinal trouble, the nature of which was not known.

On examination, she was thin and pale and ill. Movements of the shoulders and the small joints of the shoulder girdle were limited and painful. The sternomanubrial joint was tender, the chest expansion restricted, the movements of neck and spine painful and reduced to about half normal range, the sacro-iliac joints painful on compression and distraction, the hips painful and restricted, and both knees hot, tender, swollen, and limited. There was much wasting of the thigh muscles.

The remaining joints were normal and systems were normal. The haemoglobin was 62 per cent. with a low mean corpuscular haemoglobin concentration of 28 per cent. The erythrocyte sedimentation rate was $97 \mathrm{~mm}$./hr. The urine was found to be infected with coliform organisms and several excretion and retrograde pyelograms showed three functioning kidneys, two on the left and one on the right. There was an opacity in the right renal substance, presumably a stone; the urine from two of the kidneys was infected, and various antibiotics did not clear the infection. Whilst she was in hospital both wrists and both the second proximal interphalangeal joints of both hands became tender and swollen, but settled again in a few weeks. She was later transferred to the Devonshire Royal Hospital where she was observed for 3 months. Her wasted, ill state continued and did not respond to prolonged ( 2 months) rest in bed. Pain in the shoulders, sternum, spine, hips, and knees continued to dominate the clinical picture. It was decided to mobilize her, and after she began to get up she started to recover.

At follow-up one year later, at the age of 61 , she had fully recovered. No trace of the previous severe illness remained apart from a little creaking in the knees. She was symptom-free and back at work. Thirteen estimations of the S.C.A.T. in 2 years had all been negative.

Case 11, a married woman aged 54, who had suffered from stones in the right kidney for several years, noted the sudden onset of thermal paraesthesiae in the hands, which recovered but were followed in 3 days by pain in the right upper arm which persisted, and then the right shoulder became stiff. At age 56 the shoulder became worse and there was pain in the thighs and neck and stiffness of the spine. At age 57 a right nonfunctioning kidney was removed for a further stone. The left kidney was normal. The rest of the previous medical history and family history was non-contributory.

Later that year her general health was good. On examination, the peripheral limb joints were normal. The right shoulder allowed only a few degrees of painful movement. The left shoulder moved with pain through half its normal range. Both hips hurt and were limited in abduction and flexion. Pressure on the iliac crests produced pain in the region of the symphysis pubis. Straight leg raising was slightly limited and all movements of the neck and spine were much restricted and painful. The sedimentation rate was $30 \mathrm{~mm}$./hr, and the blood pressure 190/110 mm. Hg. Radiographs were normal. She was investigated in hospital but no further clues as to the aetiology of the disease came to light. She was treated with phenylbutazone $400 \mathrm{mg}$./day with signal relief of symptoms and was able to resume work, but the treatment caused indigestion and was reduced and 
then stopped. She remained well, but 2 years later, at age 58, developed extensive erythema nodosum of both legs. A chest radiograph at the time was normal. The episode was associated with some backache but no recurrence of her arthritis. At follow-up at age 62, she was completely well apart from slight symptomless hypertension. The erythrocyte sedimentation rate, however, was still slightly elevated at $24 \mathrm{~mm}$./hr. Other investigations showed no abnormality. Three estimations of the S.C.A.T. in 6 years had all been normal.

Comment.-Both these patients were female, middle-aged, and had a severe central polyarthritis with constitutional illness and raised erythrocyte sedimentation rate, from which they recovered. The severity of the disease and its excellent recovery, the central rather than peripheral arthritis, the negative S.C.A.T., the absence of nodules, and possibly also the poor symptomatic response to rest in bed, all distinguish their illnesses from typical rheumatoid arthritis. There was never any clinical or radiological evidence of ankylosing spondylitis and the erythema nodosum shown by the second patient was probably coincidental, since the arthritis associated with that condition commonly occurs concurrently and is often limited to one or two of the larger limb joints, particularly the knees. Many of the features of "periarthritis rhizomelique" (Forestier and Certonciny, 1953, 1958) are reminiscent of those shown by these two patients.

Case 12, a married shopkeeper aged 49, noted swelling of the right knee, which was followed by complete recovery after several months. At age 52 he had pain in the sternal region and took 4 weeks off work. The next year he had pain in the left knee and hip and further pain in the sternum and back. He was increasingly disabled and later that year took to his bed. He was admitted to his local hospital and improved with rest in bed and simple physiotherapy. At age 54 he was seen at the clinic for ankylosing spondylitis and thought to be an atypical case of that disease. He was treated with radiotherapy but made no definite response. At age 56 he had an acute relapse with pain in the back, chest, and shoulders, swelling of the right hand and wrist, and general illness and loss of weight. There was no history of dysuria, urethral discharge, venereal disease, conjunctivitis, or dysentery. When admitted to the Manchester Royal Infirmary, he was ill, depressed, thin, and pale, and had thickening of several metacarpophalangeal joints and proximal interphalangeal joints in the right hand. The right wrist was swollen, painful, and limited. The left hand and wrist, both elbows, and both gleno-humeral joints were normal, but the shoulder movements were limited by painful involvement of the acromio-clavicular and sterno-clavicular joints. The hips were normal, the knees showed a trace of fluid,

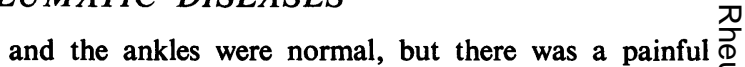
spur under the left calcaneum. The cervical spine was $\frac{}{3}$ painful and restricted and there was considerable loss of $\square$ mobility in the lumbar spine which was tender. The erythrocyte sedimentation rate was elevated $(80 \mathrm{~mm} . / \mathrm{hr}) \stackrel{.}{\Rightarrow}$ and the serum proteins were abnormal (albumin, $3.4 \mathrm{~g}$. 吕 per cent.; globulin, 4.0 g. per cent.). Radiographs ofo the spine showed calcification of interspinous ligaments $\frac{\mathrm{O}}{\mathrm{O}}$ between the first and third lumbar vertebrae. The $\overline{\bar{c}}$. sacro-iliac joints were somewhat sclerosed with some $\overrightarrow{\widetilde{\Phi}}$ scalloped erosions, but the peripheral joints showed $\varrho$ osteoporosis only. A further trial of radiotherapy to the affected acromio-clavicular joints (in which one side was $\vec{\circ}$ "mock-treated" as a control) showed no definite response. His ill state continued with frequent flares of arthritis, $\vec{\omega}$ for about 6 months, and finally settled after a course of $\stackrel{\sim}{\circ}$ gold injections, with complete resolution of all the clinical findings in the peripheral joints. At follow-up? at age 57 he was vastly improved and cheerful and had $\overrightarrow{0}$ put on weight. He was still having minor episodes of $\dot{\omega}$ joint pain and there was subluxation and crepitus in the N right first metacarpophalangeal joint. The chest expan- $\odot$ sion had improved to $3 \mathrm{~cm}$., but the lumbar spine was은 still severely limited. The bursae under both Achillestendon insertions were painful and swollen and therecs were tender calcaneal spurs under both heels. The erythrocyte sedimentation rate was normal at $10 \mathrm{~mm}$. $/ \mathrm{hr}$. Seven estimations of the S.C.A.T. had all been negative. 뭉

Comment.-This man showed some of the features $\vec{\bullet}$ of the arthritis of Reiter's disease, namely remittent course, Achilles tendon bursa and calcaneal sp involvement, spondylitis not typical of ankylosingo spondylitis, and residual spinal ligamentous calcification and sacro-iliac changes. However, there? were none of the other features usually considered $\frac{O}{\mathbb{Q}}$ essential for this diagnosis. On the other hand, the excellent recovery after a severe constitutionalō illness, the absence of nodules, the negative S.C.A.T., and the mainly central rather than peripheral joint involvement are against the diagnosis of rheumatoid? arthritis.

Case 13, a retired chauffeur, aged 65, noted aching in: the right shoulder and the symptoms later spread to theo hips, knees, wrists, and spine. The fingers were spared. When admitted to hospital the following year, he waso found to be ill with an elevated erythrocyte sedimentation rate $(78 \mathrm{~mm} . / \mathrm{hr})$ and haemoglobin 74 per cent. Heo went into a good remission after discharge and was not seen again until age 69 when he showed a little residual limitation in the right shoulder, and had developed mild bilateral Dupuytren's contracture. Previously involved joints all showed extensive juxta-articular bony proliferation and Heberden's nodes were present on the fingers. 0 He gave a history of pyelitis and dysuria at the age of 50 but otherwise his past medical history and his family history was not relevant. Four estimations of his? S.C.A.T. were all negative. 
Case 14, an electrical engineer aged 47 , noticed pain and stiffness in the neck, and 3 years later developed localized pain on the medial side of the left knee. The left knee swelled and later the small joints of the hands, wrists, elbows, ankles, and left shoulder became painful. A course of gold injections was followed by an almost complete remission lasting 8 months, when he relapsed, and a second course had no effect. However, he later went into a spontaneous remission lasting 3 years until he developed pain in the left knee and ankle. At age 60 both feet and ankles swelled each evening. He lost weight and became rather breathless but had no cough. At age 62 he was admitted to hospital, where he showed generalized enlargement of lymph nodes, and slight swelling of the metacarpophalangeal joints, wrists, and elbows. The gleno-humeral joints were normal but the acromio-clavicular joints were tensely swollen. The cervical spine and both hips were painful. Both knees were hot, tender, and swollen, and the right knee showed an effusion and flexion deformity. The erythrocyte sedimentation rate was $47 \mathrm{~mm}$./ hr. The Wassermann reaction was negative. Radiographs showed massive "fluffy" bone proliferation around the knees and for a short distance along the femora and tibia. Similar but more marked changes were present in the ankles (Fig. 1) and extended well beyond the limits of the synovial membrane. These changes suggested sub-periosteal new bone growth. There was minor bone proliferation around the hips and sacro-iliac joints consistent with osteo-arthritis. He was sent home to rest in bed and made a good functional recovery, but 3 years later there was still thickening and limitation of the wrists, elbows, and knees with flexion contractures. The hips were normal and there was considerable restriction of spinal movements. The erythrocyte sedimentation rate was again $47 \mathrm{~mm}$./hr. At age 67, at the follow-up examina-

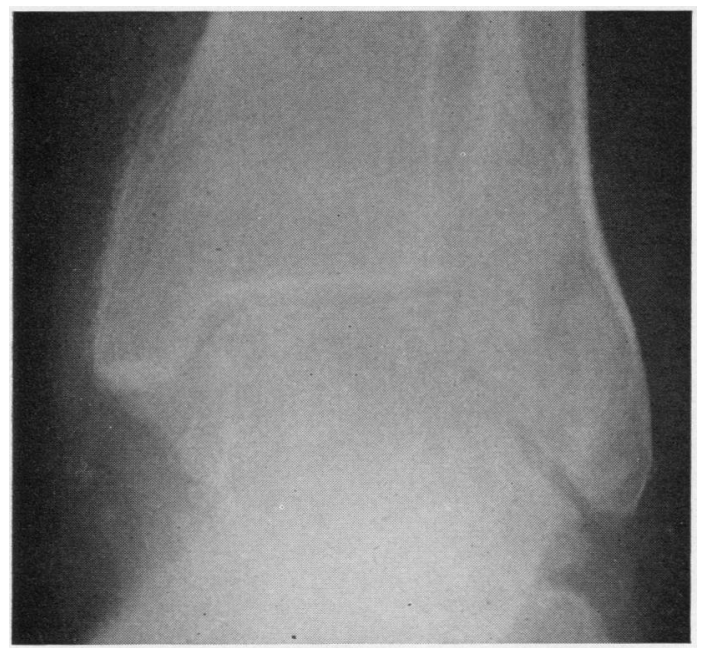

Fig. 1.-Case 14, sero-negative with atypical distribution of arthritis. Radiograph of ankle showing changes suggesting sub-periosteal bone growth. tion, both knees were still painful and hot but the left was almost ankylosed, whilst the right knee showed a limited range of movement. There was bony thickening in the kness, ankles, and elbows, but the hands were normal apart from a few Heberden's nodes, and the shoulders showed an almost full range of painless movement. The erythrocyte sedimentation rate was elevated at $31 \mathrm{~mm} . / \mathrm{hr}$. Six estimations of the S.C.A.T. had all been negative.

Comment.-Both these patients developed an inflammatory polyarthritis with constitutional illness followed by bony proliferation around the joints; in one this proliferation was marked and suggested a periosteal reaction rather than exuberant osteophytic formation. The degree of constitutional illness and the persistently elevated erythrocyte sedimentation rate in these cases, as well as the development of flexion contractures, make it unlikely that they fit in with the picture of generalized osteo-arthritis (Kellgren and Moore, 1952). They would in common usage be described as cases of "mixed arthritis", i.e. with a mixture of rheumatoid and osteo-arthritic changes. Mason, Murray, Oates, and Young (1959) have commented on exuberant periosteal new bone formation near joints and feel that "florid, fluffy new bone does appear to be a feature of Reiter's disease and of ankylosing spondylitis"; but of these diagnoses there was no further evidence in these two patients.

Case 15, a female slipper worker, had developed a swollen right knee at age 12. This was treated as tuberculous at another hospital, but subsequently the left knee swelled and a synovial biopsy did not confirm this disease. Between the ages of 15 and 23 years she could get about normally, but at age 23 the knees deteriorated and from that time the right wrist and left elbow and fourth metacarpophalangeal joint swelled and hurt and she noted pain in both hips and in the left temporo-mandibular joint. She was admitted to the Manchester Royal Infirmary at age 28 , and a further synovial biopsy showed a picture suggestive of rheumatoid arthritis. The erythrocyte sedimentation rate was raised to between 17 and $45 \mathrm{~mm}$./ hr, but all other investigations, including cultures of the synovial fluid for tuberculosis, were negative. She improved on rest in bed, salicylates, and serial splinting of the knees. When she was seen at follow-up at age 31 her functional state was good and she was able to look after a house and child. There was still swelling, tenderness, and restriction of the right wrist, left elbow, both hips, and both knees, but the spine was very mobile and the hands and feet were free of disease. The erythrocyte sedimentation rate was still elevated at $34 \mathrm{~mm}$./hr. Six estimations of the S.C.A.T. over 5 years had all been negative.

Comment.-Monarticular arthritis resembling (and often treated as) tuberculosis is a not uncommon way in which juvenile rheumatoid arthritis 
may present itself. The S.C.A.T. is commonly negative in Still's disease ( 55 per cent. of 142 cases each tested an average of 9.5 times, were consistently found to be negative by Bywaters, Carter, and Scott, 1959). However, it is questionable whether all cases of juvenile polyarthritis not otherwise diagnosed should be equated with rheumatoid arthritis as it occurs in adults.

Case 16, a farmer aged 47, developed acute pain and swelling in the left thumb and wrist after forking hay, and subsequently noted pains in the left knee, left hip, and left elbow. At age 54, he began to feel lumbar pain and stiffness, worse after heavy lifting, radiating to the lower abdomen and groins. The still swollen left wrist was explored at his local hospital but no infection was found. Subsequently there was increasing pain in the left elbow, left shoulder, and back despite excellent general health. He was admitted to hospital for increasing disability. Abnormalities were limited to the connective tissue and joints. There were large, welldefined, rubbery, cushion-like thickenings of the dermis over the hands corresponding to pressure areas where he held his farm implements. Similar large $(1 \times 2 \mathrm{~cm}$. $)$ dermal cushions had developed around the ankles and on the dorsum of the feet corresponding to sites of pressure of his boots. The left wrist was swollen and showed only $5^{\circ}$ of painful movement. There was slight general restriction of movement in the left hip. The spine was generally tender and was flattened in the lumbar region. Other joints had normal or only slightly restricted movement without swelling, although many of them were painful. The erythrocyte sedimentation rate on three occasions was $14,19,25 \mathrm{~mm}$./hr. Radiographs revealed extensive cartilage destruction and bone erosions in the left wrist and numerous Schmorl's nodes in the spine. All the investigations were normal.

The patient was treated with analgesics and a spinal support and resumed his farming, but his condition deteriorated and 2 years later at follow-up he was found to be much more crippled. There was swelling and painful limitation of both knees, both elbows, and the left ankle. The shoulders were painful and on occasions he had been unable to raise his arms. His neck was stiff and he had pain in the hips on walking. There had also been some occasional swelling in the proximal interphalangeal joints of the right hand. The erythrocyte sedimentation rate was $37 \mathrm{~mm}$./hr. Four estimations of the S.C.A.T. in 2 years were all negative.

Comment.-This man's polyarthritis was chiefly seen in the larger limb joints. Rheumatoid arthritis cannot be excluded, but the relative sparing of the small joints of the hands and feet is atypical. On the other hand there is some evidence that he may have had an underlying dystrophy which did not permit his bones, joints, and fibrous tissues to stand up to hard work in the normal way, resulting in the development of numerous Schmorl's nodes in the spine and painful arthritis of the wrist, knees, and elbows, and localized hypertrophy of the dermis over sites of intermittent pressure. These lumps were not rheumatoid nodules, nor were they the nodules of cutis elastica or pseudoxanthom\&? elasticum.

\section{Other Diseases}

Eleven patients had confirmed or probable disease other than rheumatoid arthritis at follow-up $\vec{\circ}$ psoriatic arthropathy (4), gout (1), reticulohistio: cytosis (2), Takayushu's syndrome (1), Reiter'sు disease (1), generalized osteo-arthritis (1), myelo matosis (1).

\section{Psoriatic Arthropathy}

Case 17, a baker aged 41, had developed painful feet in his early 30 s, which had continued until a generalize 9 polyarthritis developed. This was thought to be indistinguishable from rheumatoid arthritis, and he wass treated with cortisone during a large-scale therapeuti\& trial of that hormone. There was little immediateD improvement, but it was not possible to wean hip from this treatment without provoking a relapse After 6 months he returned home and gradually improyed sufficiently to resume his business, but was still tak $100 \mathrm{mg}$. cortisone daily, and continued in this way variable but continuous joint symptoms. At age about 15 years after the first onset of joint symptoms he developed a patch of psoriasis on one leg. The following year the psoriasis became generalized and he complained of weakness of the limbs. He was admitte\& to hospital where, in addition to his psoriasis, he showed painful limitation of movement in the wrists, ankles $\vec{\theta}$ and tarsal joints, with some swelling and instability i the metacarpophalangeal joints and a localized, hot ? tender active arthritis of the left midtarsal region. There were no nodules of any sort. The erythrocyte sedimen tation rate was $17 \mathrm{~mm}$./hr. A radiograph of the joints showed only slight osteoporosis with minimal evidenceof bone erosion. Nine estimations of the S.C.A.T. ove 6 years had all been negative.

Case 18, an engineer and ex-athlete aged 53, had haक a meniscus removed from the left knee at age 33 following a football injury. The next year the right knee swelle and later developed a flexion contracture. At age 34. he noted painful swelling of both big toes, which perf sisted. At age 43, the terminal interphalangeal joints of the right thumb and index fingers swelled and there was pain in other joints associated with constitutional illness and a 2-stone weight loss. When he was admitteof to hospital the following year, polyarthritis had involved a number of small joints in the hands and the involvemene of the right knee was curiously localized to the oute aspect, where there was redness, swelling, and focat tenderness. The left knee was less involved and there 
was dorsal subluxation of the lateral toes. The erythrocyte sedimentation rate was $32 \mathrm{~mm}$./hr. He was treated with gold injections, but both wrists and the right sternoclavicular joint swelled and the erythrocyte sedimentation rate rose to $70 \mathrm{~mm}$. $/ \mathrm{hr}$. At follow-up, he was still troubled by morning stiffness and painful knee contractures, but his general health was good. His hands presented a remarkable appearance, which was regarded as characteristic of psoriatic arthropathy, although he had at no time shown psoriasis of the skin. The terminal phalanges of the right thumb and index finger were grossly swollen and shortened, with deformity and patchy discoloration of the nails. The terminal interphalangeal joints of these fingers were destroyed and "flail". Similar but less advanced changes were present in the terminal joints of the right and left middle fingers, that on the left being associated with "beef sausage" appearance, i.e. uniform pink, brawny, soft tissue swelling of the whole finger, involving both joints and tendon sheaths, and easily distinguished from the moist pale lilac skin and fusiform swellings of typical rheumatoid arthritis. Both wrists showed a fibrous ankylosis, but the elbows, shoulders, neck, spine, and hips were clinically normal. Both sterno-clavicular joints and the left knee were tender and swollen but there was a relatively painless fibrous ankylosis of the right knee and the tarsal joints and lateral toes. Both great toes showed uniform brawny swelling and limitation of movement, with brown pigmentation of overlying skin and discoloration of the nail. There were no nodules. The erythrocyte sedimentation rate was $76 \mathrm{~mm}$./hr. Radiographs of the hands (Fig. 2) and toes confirmed the soft-tissue swelling and gross terminal joint destruction as well as erosions in other small joints. Eight estimations of the S.C.A.T. had all been negative.

Case 19, a woman agad 64, had first experienced polyarthritis 8 years previously; it had started suddenly in the right thumb and spread to all the fingers and toes. She was feverish despite the administration of penicillin and had lost weight. When she was seen as an outpatient, there was tender swelling of all the finger joints, massive thickening of the finger flexor tendons, and pain in all large joints. Her disease went into a remission for 5 years after a course of gold therapy, but at age 62 she again noted pain in the neck, shoulders, hands, knees and jaw, for which she received prednisolone with some benefit. When she was seen at follow-up 2 years later there was no evidence of psoriasis except for some pitting of one thumb-nail, but the arthritis was very suggestive of psoriatic arthropathy. The hands were pink, warm, and dry, and all the terminal interphalangeal joints were swollen as were some of the proximal interphalangeals, so that several fingers had the typical "beef sausage"

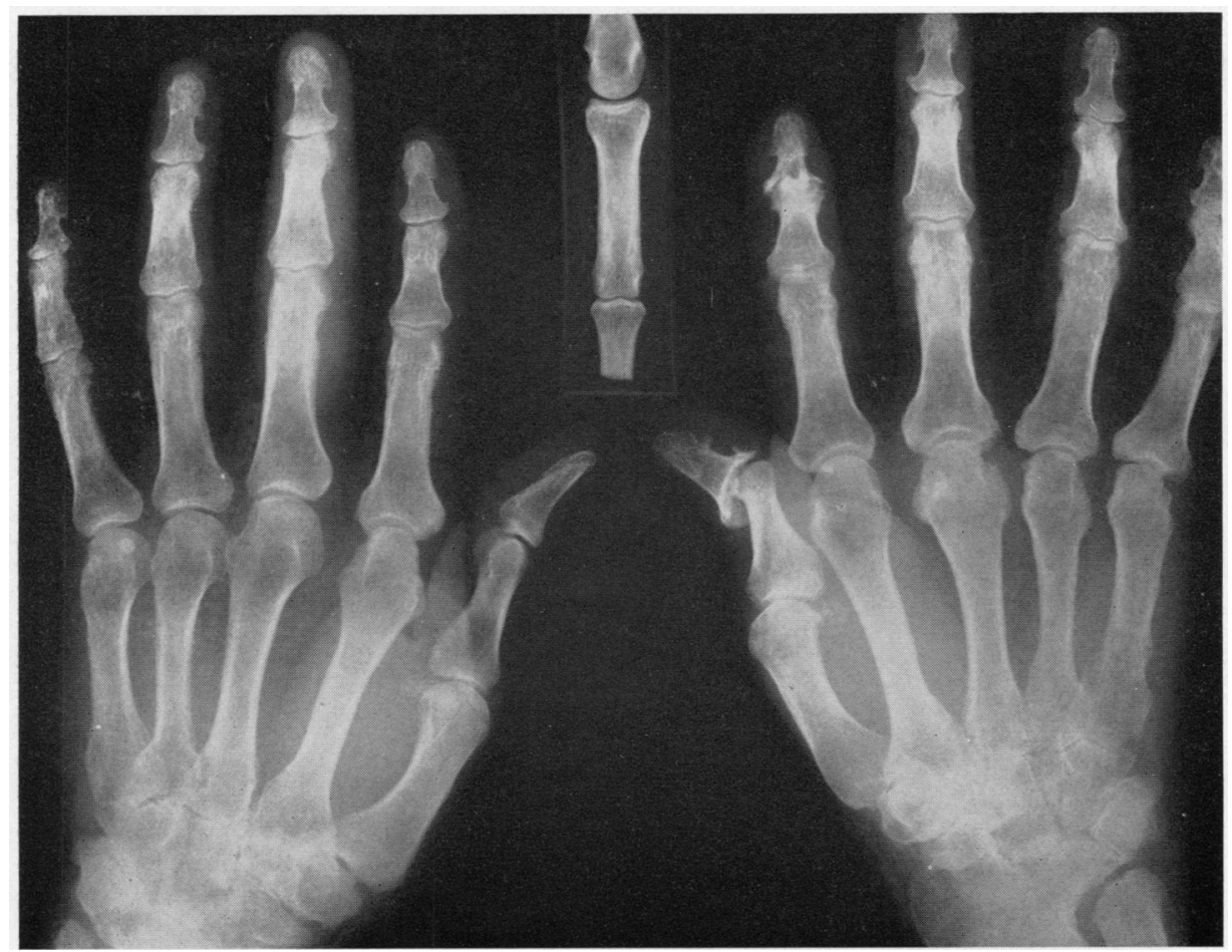

Fig. 2.-Case 18, psoriatic arthropathy. Radiograph of hands showing soft-tissue swelling, gross terminal joint destruction, and erosions in other small joints. 
appearance. However, the hands were relatively painless and still useful. There was focal pain on the medial aspect of the right knee. Both heels were tender and had in the past been a major cause of disability. There were arthritic changes in the small joints of the feet. Radiographs of the hands confirmed the extensive destructive changes in the terminal and proximal interphalangeal joints. The results of five estimations of the S.C.A.T. in 7 years had all been negative.

Case 20, a man aged 20, had had a long stay in a children's hospital for polyarthritis at age 9. The condition had healed completely but at age 16 the left foot had swelled. He was seen as an out-patient and found to have slight swelling of the interphalangeal joints of the fingers in addition to a warm, tender left tarsus and big toe, and a localized area of warmth, tenderness, and swelling near the left lateral tibial condyle with limitation of knee flexion. The chest expansion and spinal movements were slightly limited and the erythrocyte sedimentation rate was $37 \mathrm{~mm}$./hr. Later in the same year he was admitted to hospital because of a relapse with fever and acute polyarthritis. He was treated with rest in bed, aspirin, and suitable plasters, but 5 months later developed a large effusion in the right knee and the right tarsus became painful. He was also noted to have a right Achilles tendinitis. From these troubles he made an excellent recovery. When seen at follow-up at the age of 20 he was well, at work, and indulging in strenu- $\frac{\Phi}{5}$ ous sports. However, the right knee was still swollen and contained an effusion, the chest expansion was $3 \mathrm{~cm}$., and all spinal movements were restricted. Radiographs? of the hands, knees, and feet were normal but there was almost complete obliteration of both sacro-iliac joints (Fig. 3), the changes being more pronounced on the right. He gave a previous history of acute psoriasis $\frac{\bar{c}}{\bar{\omega}}$. at age 7, which had been diagnosed and treated in $a \frac{5}{\sigma}$ hospital for skin diseases, but which had cleared up@ entirely before his polyarthritis had begun. The results? of five estimations of the S.C.A.T. had all been negative. $\overrightarrow{0}$

Comment.-No definition of psoriatic arthropathy has been universally accepted. There is fairly $\vec{\omega}$ general agreement that the inflammatory arthritis confined to the terminal interphalangeal joints,, associated with nail changes on the corresponding $\overrightarrow{0}$ fingers, deserves to be considered as an entity. separate from typical rheumatoid arthritis. Such 0 changes, however, may also occur as part of $a^{\bullet}$ general polyarthritis, with or (as in Case 18) without psoriasis of the skin. Most authors who have $\vec{c}$ studied the S.C.A.T. or related agglutination reactions have noted that these tests are usually negative $\frac{\vec{D}}{\mathrm{D}}$ in, and rheumatoid subcutaneous nodules usually absent from, patients who show psoriasis with any్ㅡㅁ

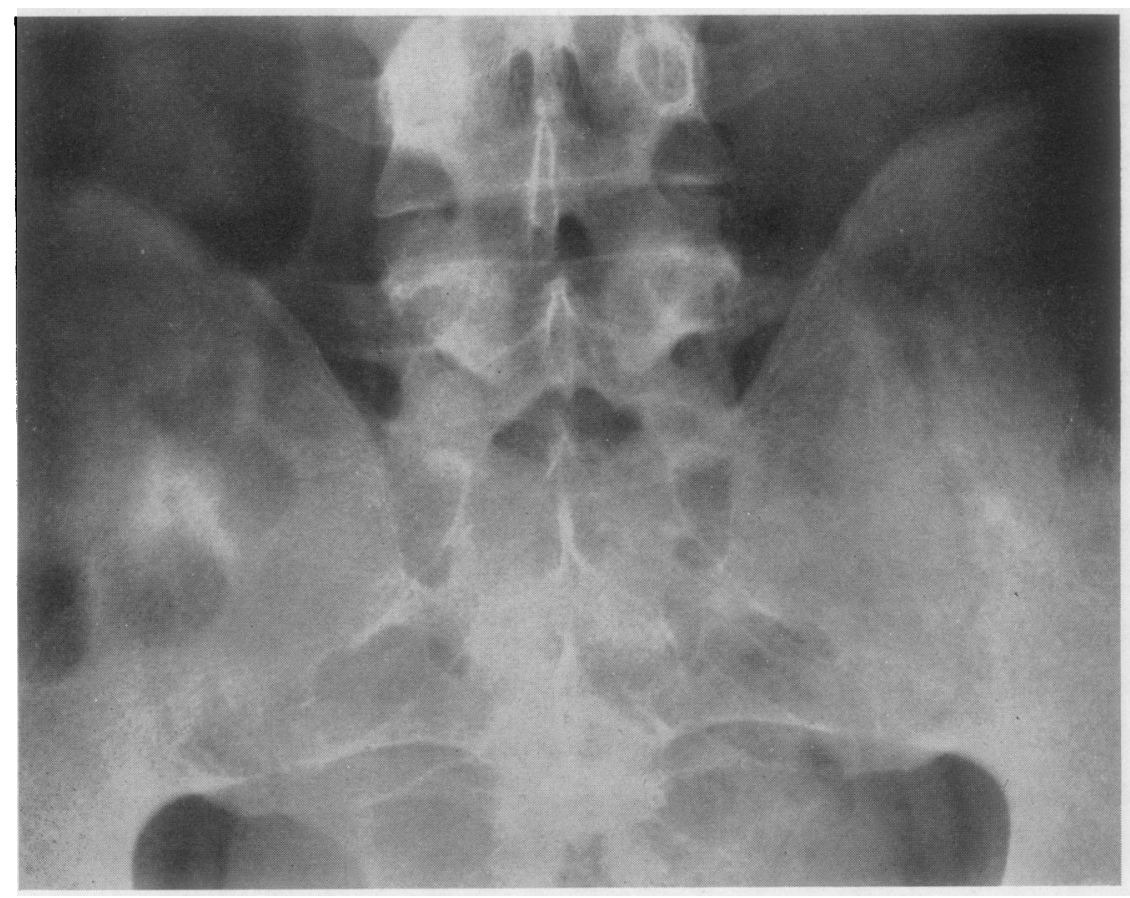

Fig. 3.-Case 20, psoriatic arthropathy. Radiograph of pelvis, showing almost complete obliteration of sacro-iliac joints, more pronounced on the right. 
form of arthritis (Kellgren and Ball, 1959; Ziff, 1957; Wright, 1957, 1959; Jacqueline, Podliachouk, and Eyquem, 1956; and many others). These negative associations are so frequent as to make it likely that most cases of arthritis associated with psoriasis represent a disease or diseases distinct from rheumatoid arthritis. Other clinical features sometimes (but not invariably) present to help differentiate the arthritis of this condition include:

(1) Acute, often gout-like onset;

(2) Focal areas of tenderness and inflammation around large joints;

(3) Severe destruction in some joints with complete sparing of others;

(4) A mainly large-joint distribution;

(5) Where the fingers are involved, cylindrical brawny swelling with pink, warm, and often dry overlying skin - the "sausage finger" of Weissenbach (1938).

(6) A tendency for destructive arthritis of the terminal interphalangeal joints often associated with discoloration and subungual hyperkeratosis of the corresponding nail;

(7) Radiological appearances of bone proliferation as well as destruction around involved joints.

The degree of psoriasis bears no relationship to the amount of arthritis with which it may be associated, and varies from generalized exfoliation to small inactive patches of rash, often hidden in the navel or around the anus, and easily missed. Moreover, the rash may clear up entirely in cases showing persistent arthritis, only to reappear from time to time. Many patients give a history of noticing arthritis before the psoriasis (as in Wright's series), and Wright (1957) has written: "It is tempting to suggest that some cases of erosive arthropathy with a negative differential agglutination test are destined to develop psoriasis", a sequence which was observed in Case 17 after 15 years of arthritis. Sharp (1957) has called attention to the association of psoriasis and atypical spondylitis seen in the fourth of these cases.

\section{Gour.-This was seen in one male patient.}

Case 21, a robust police inspector aged 48, developed pain in both feet, of gradual onset, later spreading to all major joints, as well as the fingers, jaw, and neck. There was no family history of arthritis. When he was first seen at age 46, his hands were pink and cool, and there was slight limitation of movement in all finger joints, as well as of the shoulders, hips, and neck. The haemoglobin and white cell count were normal, but the erythrocyte sedimentation rate was $33 \mathrm{~mm}$. $/ \mathrm{hr}$. A diagnosis of rheumatoid arthritis was made. At follow-up, at age 48, there was improvement in the joints but small nodules had appeared on both elbows. The haemoglobin and white cell count were still normal, the erythrocyte sedimentation rate was $19 \mathrm{~mm}$./hr, and two estimations of the serum uric acid were $5 \cdot 2$ and $6 \cdot 8 \mathrm{mg}$. per cent. respectively. Radiographs showed ill-defined cystic changes in the bone ends, which were picked by an independent observer unaware of the clinical findings, as more suggestive of gout. Further investigation had not been permitted. The results of five estimations of the S.C.A.T. were all 4 or less.

Comment.-The evidence for gout lacks proof, but nevertheless, Ludwig, Bennett, and Bauer (1938) noted gout presenting in such a manner, and this diagnosis seems at least as tenable as that of rheumatoid arthritis. In no other case in this follow-up series was the serum uric acid level raised, and the two observations recorded here are unlikely to be due to experimental error.

Reticulohistiocytosis.-Two patients were thought to have reticulohistiocytosis (Warin, Evans, Hewitt, Taylor, Price, and Middlemiss, 1957) and in one, biopsy proof was obtained.

Case 22, a married woman aged 39, was well until age 33 when she experienced prurigo of the hands, without visible rash, lasting 3 months; 9 months later her fingers became cold, white, and painful, and small nodules and tiny translucent papules developed on the backs of the fingers and around the nails. The fingers became stiff and so painful that, at age 34 , she was referred for surgical treatment of the Raynaud's phenomenon, but this was not done because the condition improved spontaneously. She was admitted to the Manchester Royal Infirmary, at age 35, for pain and stiffness in wrists, elbows, shoulders, feet, and knees associated with weight loss, generalized lymphadenopathy, and nodules, not only in the dermis of the fingers but also attached to the finger flexor tendons and around the wrists and ankles. There were objective signs of arthritis of the elbows, wrists, and knees, and all other joints except the spine were painful. The erythrocyte sedimentation rate was only slightly raised, and the blood count, serum proteins, and urine were normal. She was initially considered to have a rheumatoid arthritis in which connective tissue changes were severe whilst inflammatory reactions were slight. A course of gold injections was started and the patient returned home, since when she has managed with gradually increasing difficulty. Her son, aged 12, was normal, but her mother, who was at that time normal, later developed a polyarthritis of hands, wrists, and feet, and her aunt, too, had had some form of rheumatism.

At follow-up examination the patient was of normal build and colour. Her disabilities arose mainly from an enormous number of small nodules. In the hands these were 1 to $5 \mathrm{~mm}$. in size, rounded, raised, painless, firm, brown or violet, intracutaneous granulomata, and occurred in the pulps as well as on the backs of the fingers. A particular feature was the presence of a 


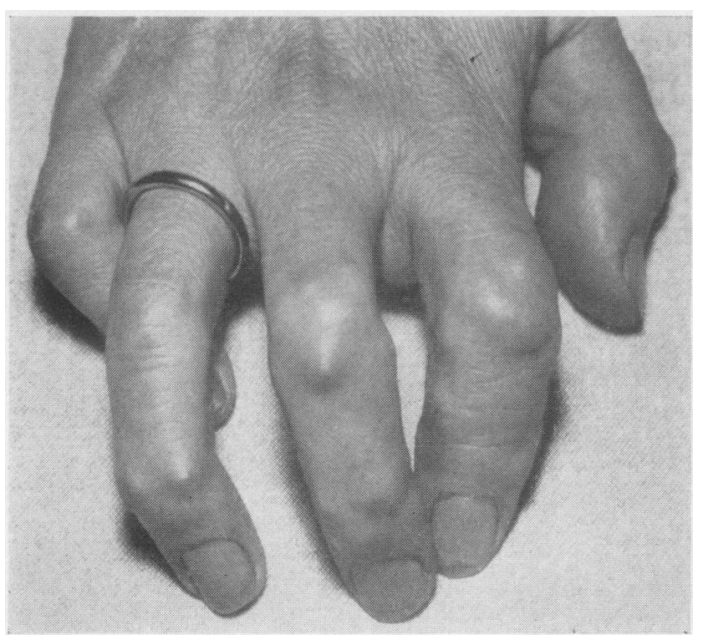

Fig. 4.-Case 22, reticulohistiocytosis. Nodules on fingers.

corona of tiny granulomata in the edge of the nail fold at the base of each nail (Fig. 4). Other nodules affected the tendons, which were massively enlarged both in the palms and on the extensor surfaces. Limitation of finger movement was probably due to impaction of these tendon nodules in their sheaths. There were similar nodules in the Achilles tendons and around the ankles. In the forearms and feet the tendon nodules produced a "beaded" appearance. There was no generalized rash, and despite a careful search only three small lesions involving the skin were found elsewhere than on the fingers. One, $2 \mathrm{~mm}$. in diameter, was present over one knee and there were two over the left elbow; the latter were removed for histological examination. There were no xanthelasma and no mucous membrane changes. Small effusions were demonstrable in both $\stackrel{\overrightarrow{5}}{+}$ knees and there was dorsal subluxation of the lateral $\overline{0}$ toes as seen in rheumatoid arthritis. The wrists con- $\frac{\bar{C}}{\sigma}$ tained small effusions and there was some swelling of $\overline{\bar{\omega}}$ both second and third metacarpophalangeal joints with $\vec{D}$ lesser swelling of other knuckle and finger joints. The $\varrho$ general physical condition was otherwise normal. The ڤ haemoglobin was 80 per cent., total white cell count $\vec{\circ}$ 7,100 cells per c.mm., differential cell count normal, serum uric acid $3.5 \mathrm{mg}$. per cent., and erythrocyte $\vec{\omega}$ sedimentation rate $32 \mathrm{~mm}$./hr. The biopsy was reported (by Dr. J. Ball) as follows:

"Reticulohistiocytoma. The middle and lower dermis is occupied by a nodule (approximately $1 \mathrm{~mm}$. in diameter) $\vec{\varphi}$ consisting of cells with one, two, or several nuclei. The $\omega$ nuclei are pale, the cytoplasm abundant and without $N$ conspicuous granules. The multi-nucleate cells give a 0 weak reaction for lipid with Sudan black, which dis- 음 appears after extraction with hot methanol and chloro- $\vec{\longrightarrow}$ form. Mild acid hydrolysis does not increase the uptake $\vec{i}$ of Sudan-type dyes. There is some periodic-acid-Schiff- $\mathbb{D}$ positive material in the cells, not removed by fat extraction. None of these reactions is strong, but they suggest $\stackrel{(D)}{7}$ that the cytoplasm may contain both lipid and neutral polysaccharide."

Radiographs of the knees (Fig. 5), hands (Fig. $\oint \vec{\oplus}$ left foot (Fig. 7B), and pelvis were taken, and radiographs of the hand and feet which had been taken during her previous stay in hospital were available for compariso? These showed gross cystic defects of bone in the sub-

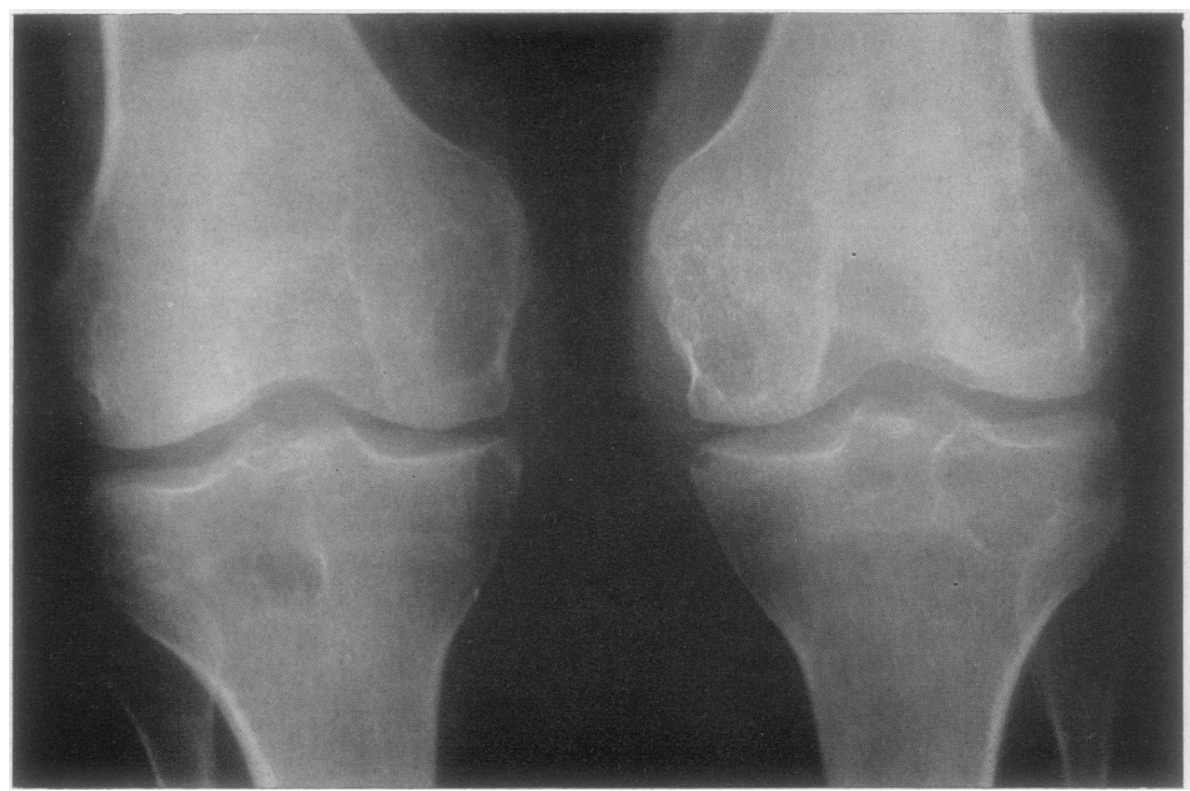

Fig. 5.-Case 22, reticulohistiocytosis. Radiographs of knees. 

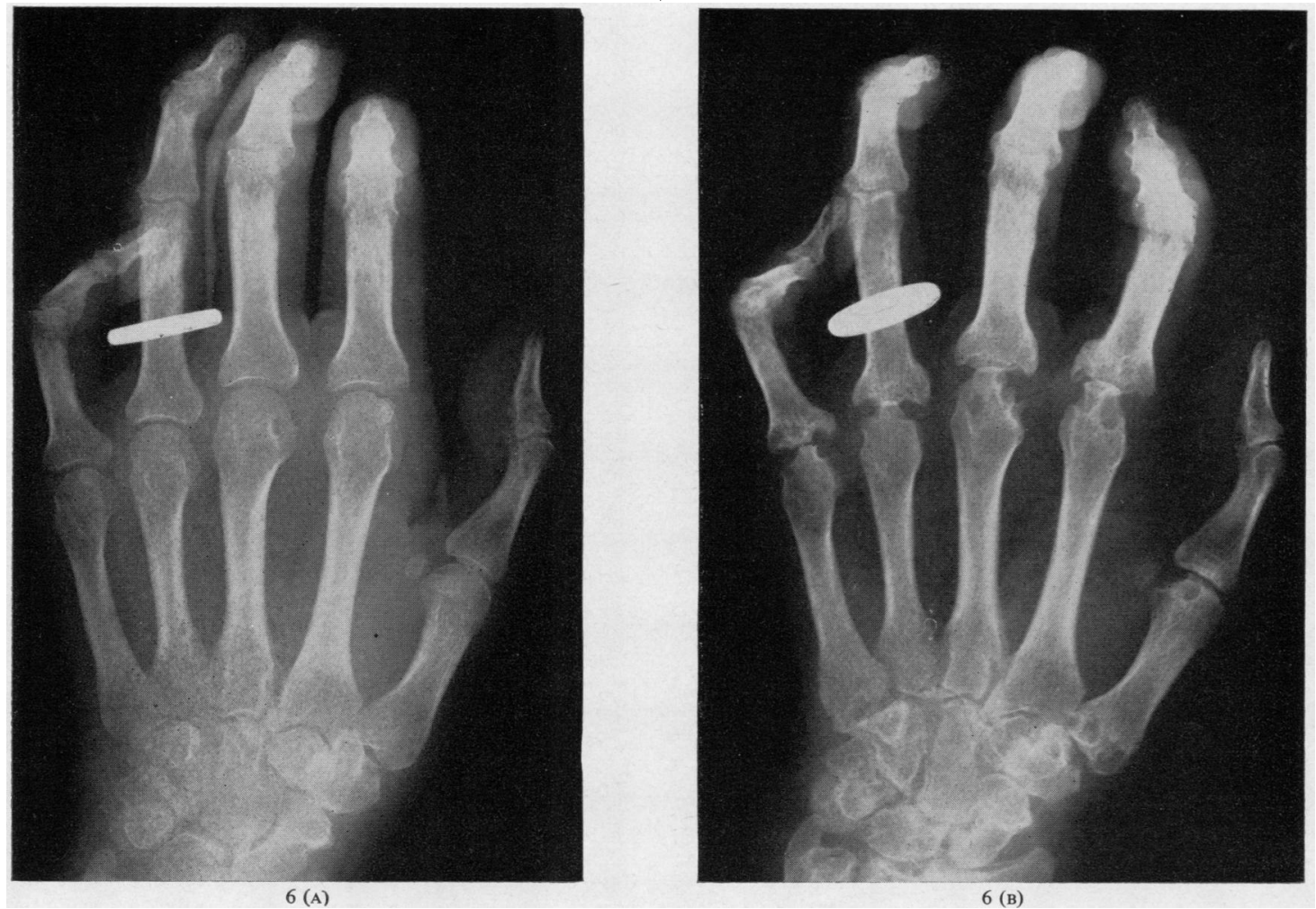

Fig. 6.-Case 22, reticulohistiocytosis. Radiograph of left hand when first seen (A) and 4 years later (B). Flexor deformities of fingers result from tendon nodules. Deposits near joints mimic rheumatoid arthritis.

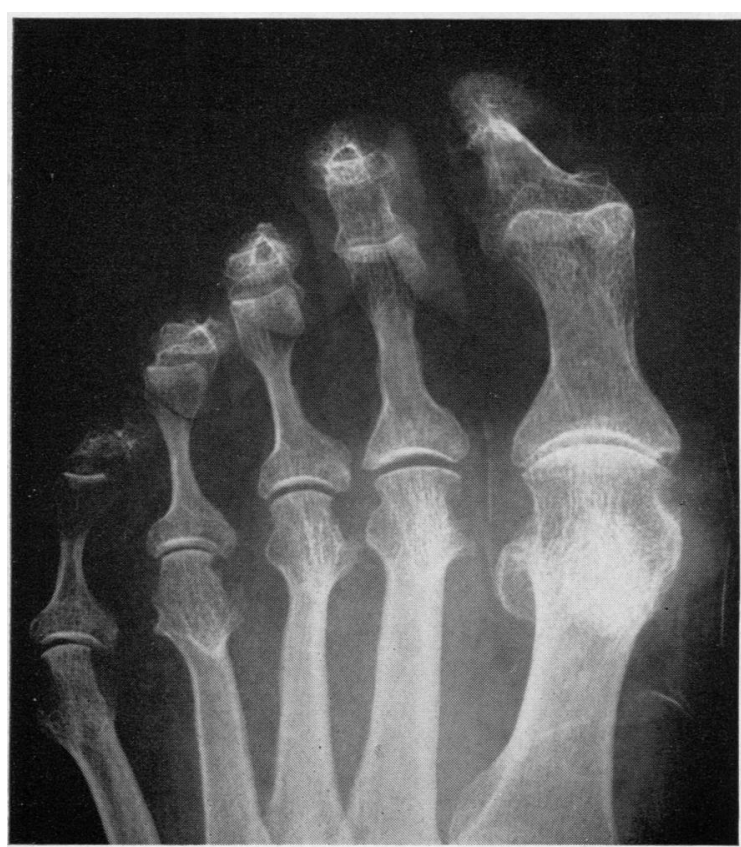

7 (A)

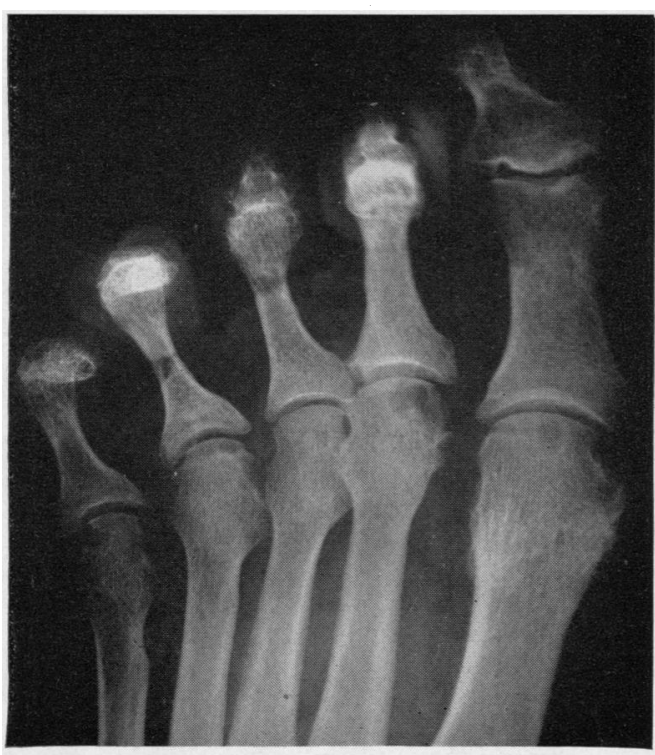

7 (в)

Fig. 7.-Case 22, reticulohistiocytosis. Radiograph of left foot (B). The corresponding foot of Case 23 (the patient's mother-not one of our follow-up series) shows typical rheumatoid arthritis (A). 
chondral regions. The "cystic" appearances had the largest diameter in the knees. In the hands the "cysts" were smaller and appeared to have broken through into the joint space itself. The articular cartilage, where not involved by a "cyst", retained its normal thickness and the bones were not particularly porotic.

Case 23, the mother of Case 21, was not seeking medical advice, but was seen to have hand and wrist changes which appeared to be due to typical rheumatoid arthritis. Full examination was not permitted, but reticulohistiocytic skin lesions were not present on the hands, feet, and face. There was an early Dupuytren's palmar fascial thickening opposite the right and left third and fourth fingers, without contracture, and both wrists were tender, swollen, and limited. The second and third metacarpophalangeal joints were also swollen and flexed. There were small but significant flexor tendon nodules, rheumatoid deformities of the toes, and a discharging sinus over a left hallus valgus. Radiographs of her hands and feet were taken, the latter (Fig. 7A) being practically identical with those shown by her daughter. No blood test was obtained for S.C.A.T., but the possibility that the mother also had this disease could not be excluded. If she did not have reticulohistiocytosis, the radiographs illustrated the great resemblance between this disease and rheumatoid arthritis.

Comment.-The comparative absence of skin lesions in Case 21 was intriguing. It was tempting to suppose that patients might exist who would show the condition without any skin lesions, and accordingly the patients in this study were reviewed with this in mind. One patient showed large tendon nodules and her radiographs showed cystic defects of bone with relative preservation of bone density.

Case 24, a woman aged 51, developed painful knees at age 41. At age 47 she developed generalized polyarthritis and the following year was found to have thickening of the flexor tendons in the hands, swelling of the small joints of hands and feet, and large effusions in the knees. She was thought to have typical rheumatoid arthritis and was treated with gold injections. She again improved until age 56, when there was a slight recurrence of stiffness. She was deaf and gave a family history of otosclerosis. At the follow-up examination the striking finding was that of large, visible, crepitant nodules in the flexor tendons of the hands. The finger joints were limited in range and a little tender, and all other joints showed slight painless limitation of movement. There were no skin nodules or rash. The haemoglobin was 90 per cent., white cell count normal, and serum uric acid $3.5 \mathrm{mg}$. per cent. A radiograph of the hands (Fig. 8, opposite) was reported (by Dr. G. B. Locke) as showing "very pronounced cystic changes in the lower end of each radius, carpal bones, the base of the thumb metacarpals and subarticular region of the metacarpophalangeal joints". The S.C.A.T. was tested over a period of 5 years and was negative on each occasion.

\section{TAKAYUShU's SyNDROME}

Case 25, a woman aged 50, had had chorea at age 17.

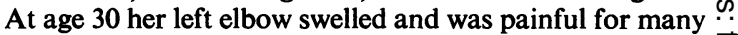
months. At age 33 she became pregnant and with the $\overrightarrow{\bar{F}}$ pregnancy became ill. The foetus died at 3 months but was not delivered until the 6th month. Subsequently the patient developed severe Raynaud's phenomenon, $\frac{\bar{\sigma}}{\bar{D}}$ with recurrent attacks of colic, diarrhoea, and vomiting. $\frac{5}{\partial}$ A laparotomy was performed for one of these attacks, $\stackrel{\mathbb{Q}}{\varrho}$ signs of a peritonitis were found, and the patient was nursed in a sitting position. During this time both knees became stiff and painful and the pains later spread $\overrightarrow{0}$ to the wrists, elbows, shoulders, and back. At age $46 \vec{\overrightarrow{ }}$ her health deteriorated, she noted flitting areas of skin soreness, many reddish nodules, and bruising. At age 48 there was sudden, severe, lower abdominal pain spreading $\bar{\alpha}$ to the back, and a week later sudden pain in the left $\vec{\oplus}$ calf, with claudication and pain on walking. There were episodes of patchy swelling and pain about the head and $i v$ face, and she was breathless on exertion. She was 8 admitted to hospital because of increasing pain from 음 her knees and because of the claudication.

The pulses were absent in the left leg and variable in $\vec{\omega}$ the right arm. The peripheral arteries, including the $\mathbb{D}$ carotids, were thickened, and the carotid sinus was $\frac{\vec{D}}{\vec{D}}$ sensitive to very slight pressure. There were clinical $\frac{\sqrt{3}}{3}$ and radiological signs of a slight mitral stenosis. The presence of oesophageal varices, disturbed liver function tests, facial pigmentation, and telangiectases suggestå $\vec{\bullet}$ hepatic cirrhosis. Shortly after her admission to hospita the right foot became pulseless. She was given and: coagulants and corticosteroids with relief of pain, bẹt developed further evidence of arterial occlusion in the coronary and possibly renal arteries. She died from $\overline{0}$ left ventricular failure. Post mortem examination was not permitted.

The joint findings are best described as a "subluxing $\overrightarrow{\vec{D}}$ arthropathy", i.e. there was gross dislocation of the toes $\frac{0}{3}$ at the metatarsophalangeal joints, and of the carpus at the wrist joints, with only minimal changes in subchondral bone, despite a generalized osteoporosis. The "erosions" or defects seen could probably be regarded as secondary to the subluxation, rather than as evidence of an erosive synovitis (Fig. 9, opposite).

The erythrocyte sedimentation rate was $80 \mathrm{~mm} . / \mathrm{hr}, \stackrel{3}{3}$ and the white cell count normal. Repeated search for $ᄋ$ L.E. cells was unsuccessful. The S.C.A.T. was negative on nine occasions over a period of 8 months just before 음 the patient's death.

Comment.-This patient showed evidence of a generalized arteritis with progressive occlusion. The $\mathrm{N}$ long history of illness, the sensitive carotid arteries, $N$ the thickened arteries generally, the scattered $N$ nodular rash, the raised sedimentation rate, sug- $\sigma$ gested "young female arteritis" of Takayushu's disease (Takayushu, 1908). Nine out of 28 such $\stackrel{0}{\frac{C}{1}}$ patients reviewed by Ask-Upmark (1954) had some evidence of generalized rheumatism, and a similar proportion in his second review (Ask-Upmark and 


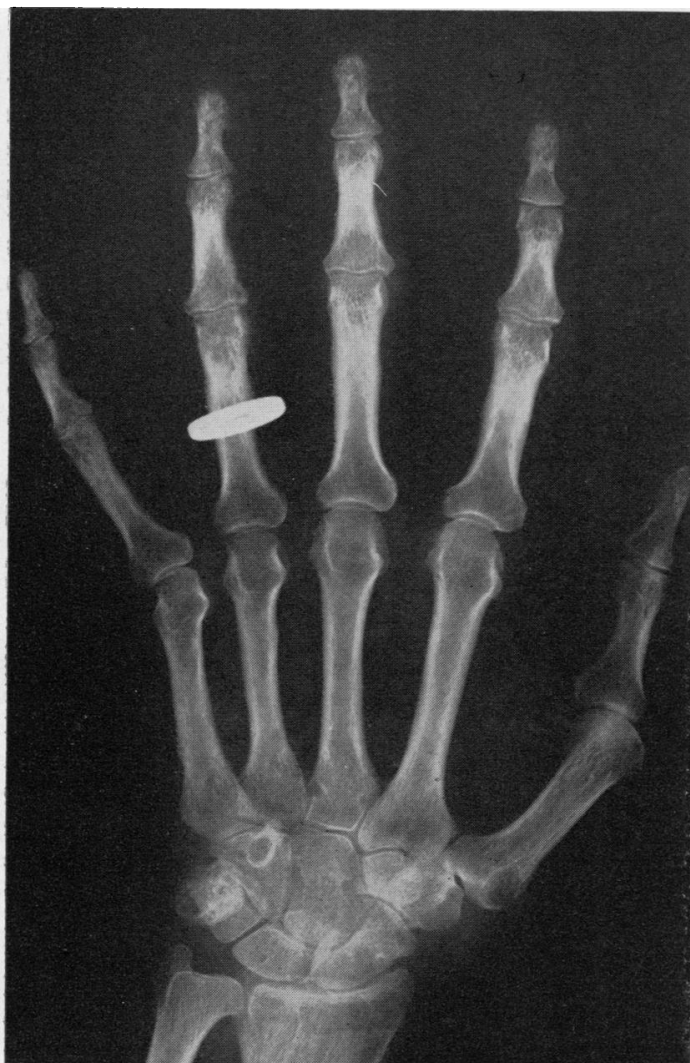

8 (A)

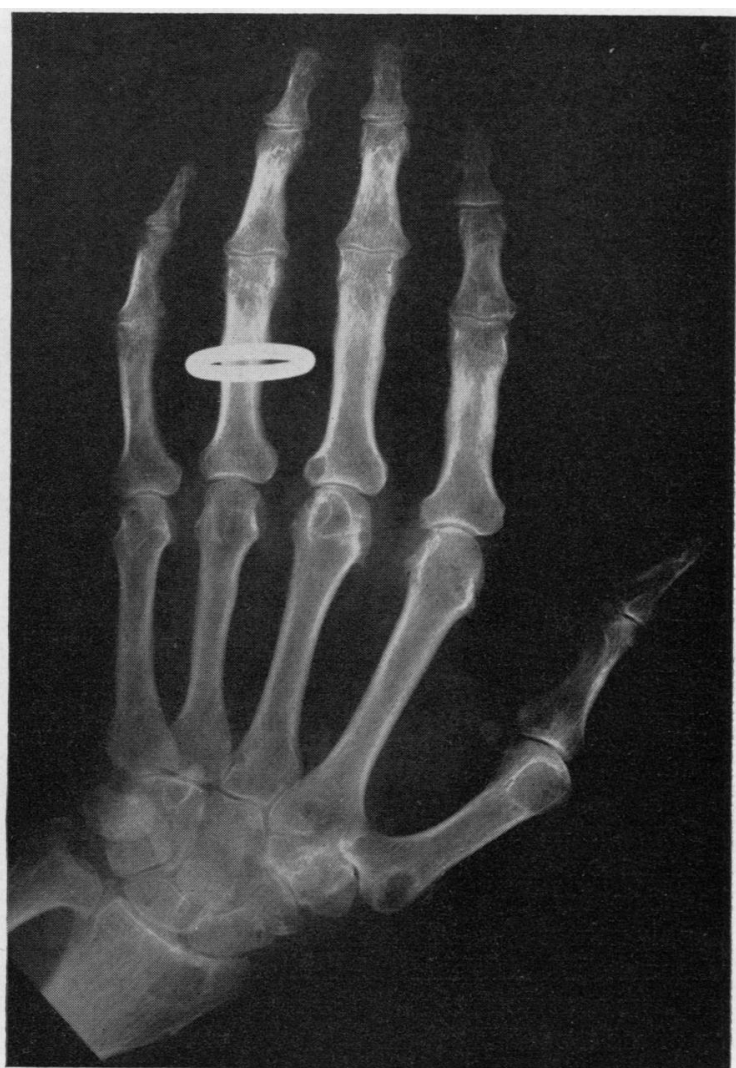

8 (в)

Fig. 8.-Case 24, possible reticulohistiocytosis. Radiograph of left hand when first seen (A) and 5 years later (B). Flexion contractures of the fingers result from large tendon nodules. "Cysts" near joints are compatible with rheumatoid arthritis or reticulohistiocytosis.

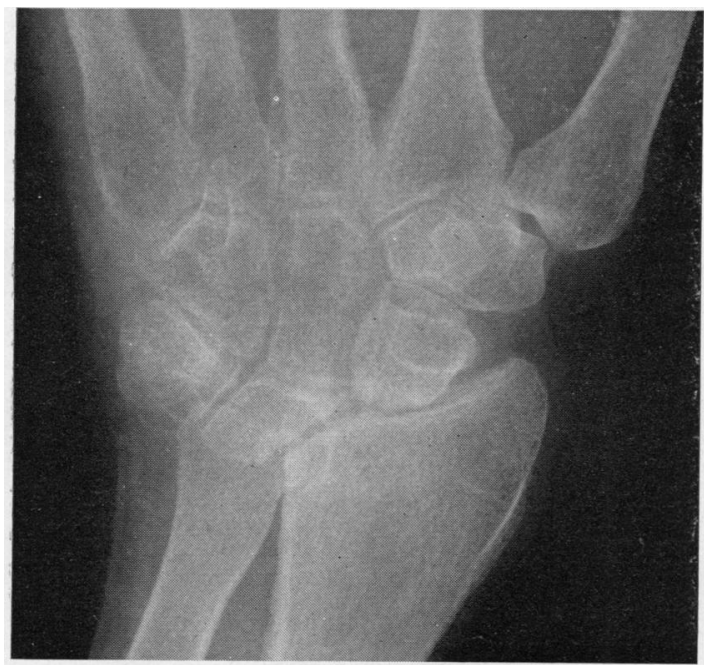

Fig. 9.-Case 25, Takayushu's syndrome. Radiograph of wrist, showing subluxation.
Fajers, 1956). It is suggested that the arthropathy noted can best be regarded as part of the Takayushu syndrome, since it was neither clinically nor serologically typical of rheumatoid arthritis. Alternative diagnoses, unlikely but not excluded by the evidence available, were polyarteritis nodosa affecting mainly the larger arteries and Jaccoud's syndrome (Bywaters, 1950).

\section{Myelomatosis}

Case 26, a housewife aged 45, developed pains in the right hand, right scapula region, and back, worse at night. 8 months later she developed symptoms referable to many joints with swelling in front of the wrists. Movement of the fingers was limited by thickening of the flexor tendons. A biopsy of the tendons showed a featureless granulomatous material. Her condition worsened, and a year after onset she showed swelling of the second and third metacarpophalangeal joints of the right hand and there was pain in many other small joints of the hands. The outer metatarsophalangeal 
joints were painful and subluxed and effusions were present in the knees. She was pale and ill but physical examination disclosed no other abnormalities. The erythrocyte sedimentation rate was $42 \mathrm{~mm}$./ hr, serum albumin $4 \cdot 2 \mathrm{~g}$., and globulin $2 \cdot 2 \mathrm{~g}$. per cent. The haemoglobin fell from 60 to 48 per cent. The white cell count was normal or low on several occasions. The serum uric acid was $5.5 \mathrm{mg}$. per cent. The urea clearance was subnormal, and the urea showed a fixed specific gravity. Protein was absent from the urine until about 13 months after the onset of disease, when a proteose was found; 3 months later this proteose showed the characteristics of Bence Jones protein. A review of the previous biopsy and other investigations did not disclose any diagnostic evidence of myelomatosis. She was discharged to her home but was re-admitted 18 months after the first onset with anaemia, leucopenia, pain in most joints, contractures of the knees, and a nodule on one elbow. Radiographs taken a few days before her death showed erosions of articular bone in one hip and also changes in the long bones and pelvis "suspicious of myelomatosis". Previous radiographs had all been normal. Five estimations of the S.C.A.T. had all been normal. At autopsy widespread myelomatosis was found.

Comment.-Rheumatoid arthritis could not be excluded on clinical grounds, and was indeed the diagnosis for most of the course of the disease. A polyarthritis, mainly of the small joints, with "rheumatoid" deformity of the toes, effusions into and later contractures of the knees, nodular thickening of the tendons in the hands, and a subcutaneous nodule on the elbow all pointed to this diagnosis. Proteosuria was the first definite sign of myelomatosis, but before this the negative S.C.A.T. had indicated that rheumatoid arthritis was possibly not the correct diagnosis. The granulomatous deposit in the wrist was probably the "para-amyloid" sometimes seen in myelomatosis.

\section{Reiter's Disease AND AORTITIS}

Case 27, a motor driver aged 36, had developed at age 32 a non-gonococcal urethritis followed by stiffness of the back and hips and pains under the right heel and in both shoulders, the neck, right wrist, and right ankle. Moderate disability for 3 years was followed by a relapse with illness, orchitis, back pain, and transient conjunctivitis. He was admitted to hospital and was found to be pale and ill with signs of a free aortic regurgitation. The lower spine was almost rigid and there was active arthritis of the knees, left shoulder, right wrist, right ankle, and first metatarsophalangeal joints, with regional muscle wasting. The erythrocyte sedimentation rate was $84 \mathrm{~mm} . / \mathrm{hr}$, and haemoglobin 76 per cent. The electrocardiogram showed a prolonged $P-R$ interval $(0.4 \mathrm{sec}$.). Radiographs showed only osteoporosis around the involved joints. A small amount of fluid, of normal appearance but with an increased cellularity, was aspirated from one knee. At age 38 the patient died during an emergency laparotomy for intestinal obstruction, but no post mortem examination was made. The clinical diagnosis was "rheumatoid arthritis" with aortic valve disease, presumably rheumatic. Sixteen estimations of the S.C.A.T. had all been negative.

Comment.-This patient showed the syndrome of spondylitis, peripheral joint involvement, and free aortic regurgitation associated with a prolonged $\mathrm{P}-\mathrm{R}$ interval which has been described by a number of authors since the original publication of Clark and Bauer (1948). These workers regarded the syndrome as a variant of rheumatoid spondylitis, and others (Graham and Smythe, 1958) as a form of ankylosing spondylitis, but I feel, for a variety of reasons, that it is best regarded as a complication of Reiter's syndrome.

\section{Primary Generalized Osteo-Arthritis}

Case 28, an unmarried woman aged 61, was admitted to hospital in 1956 with painful joints and stiffness of the neck of one year's duration. She had previously noted episodes of pain and swelling in the knees. Her general health was excellent and she had gained weight. The physical and radiological findings were those of a generab ized osteo-arthritis, but the severity of symptoms ang high erythrocyte sedimentation rate $(83 \mathrm{~mm} . / \mathrm{hr})$ sus gested rheumatoid arthritis. The following year she had lost all disability, but had the deformities of osteoarthritis, namely Heberden's nodes, adducted thumbs with bony enlargement of the carpometacarpal joints, painless bony enlargement of other finger joints and knees, and limitation of movements in the lower neck. The erythrocyte sedimentation rate had fallen to 47 $\mathrm{mm}$./hr. Four estimations of the S.C.A.T. were all negative, and there was never any evidence of subcutaneous nodules, nor were erosions seen in the bone radiographs.

Comment.-A moderate rise in the erythrocyte sedimentation rate may accompany primary generalized osteo-arthritis (Kellgren and Moore, 1952), but elevation to this degree is exceptional. All other features of this patient's illness pointed to that 을 diagnosis, however, and away from the diagnosis of rheumatoid arthritis.

\section{Discussion}

The correlation of a positive S.C.A.T. and the fully-developed picture of rheumatoid arthritis with $\omega$ nodules is practically 100 per cent. (Kellgren and Ball, 1959), an outstanding result for any biological 0 diagnostic test. Compare, for example, the cor- $\mathbb{D}$ relation of the antistreptolysin titre and Group-A $\stackrel{+}{+}$ $\beta$-haemolytic streptococcal infection which is 80 per 
cent. (Mote and Jones, 1941). The association of severe "rheumatoid-like" chronic polyarthritis and a negative S.C.A.T. is therefore apparently exceptional; such a situation might arise from several causes, related either to the disease or to the test. Population studies (Kellgren and Lawrence, 1956) show a continuous curve for the distribution of titres in the test, the usual dividing line of a limiting dilution of 1 in 32 is arbitrary and is based on the best correlation with clinical findings in a group of patients. A lower titre might be significantly "positive" for an individual patient. Like all serological tests it is subject to one- or even two-tube errors. In this study repeated testing and a titre of $1: 8$ as highest acceptable negative should have minimized these effects. Others have reported on the presence of circulating inhibitors of the S.C.A.T. separable by fractionation of serum. Both the absence of such inhibitors, or their removal to leave a positively reacting residue, have been regarded as diagnostic of rheumatoid arthritis (Ziff, Brown, Lospalluto, Badin, and McEwen, 1956). Sera from all the patients who remained sero-negative in this study have been tested for inhibitors in a similar way, so far fruitlessly, perhaps for technical reasons. Both in juvenile rheumatoid arthritis (Bywaters, Carter, and Scott, 1959) and in surveys of the adult population, especially in the first three decades, the frequency and titre of positive S.C.A.T. tests increases with age. The average age of the patients under study was 52 years, which is beyond the range at which age noticeably influences these results. Nevertheless, the age-effect may explain the low titres in the two patients under 30 years of age at the time of follow-up. Thus, these several technical considerations related to the test cannot explain the persistently negative results seen in the majority of these patients. Considerations related to the disease, on the other hand, do explain some cases, particularly those eleven patients who were found at follow-up to have proved or probable diseases other than rheumatoid arthritis. Hall, Mednis, and Bayles (1958) have noted a similar experience. In our twelve patients who eventually developed a positive S.C.A.T., the majority (ten) also developed a completely typical clinical picture, with symmetrical involvement of peripheral joints, and in most cases, rheumatoid olecranon nodules. It seems likely that the original arthropathy, though sufficiently widespread and active to qualify for this study, was in fact a manifestation of an incomplete development of the total disease of rheumatoid arthritis. We may note the duration and marked severity in Case 2, who developed severe, progressive arthritis, yet 15 years after onset was still sero-negative, despite fibrinoid necrosis of sub-synovial tissue. Sero-conversion was not observed until 23 years after onset, by which time crippling destructive changes had taken place. Parenthetically, it is possible that repeated and non-rheumatoid arthropathy might lead to a generalized rheumatoid arthritis by way of a sensitization reaction, in the same way as accidental or operative trauma to a joint sometimes appears to be followed by the development of generalized rheumatoid arthritis. This kind of sequence seemed possible in Case 3 with a 12-year history of intermittent hydrarthrosis, limited until quite recently to the knees.

The S.C.A.T. may become negative in patients who are doing well (De Forest, Mucci, and Boisvert, 1956) and we have seen several examples of this sequence. The opportunity to continue observations on the S.C.A.T. after a remission of both blood pathology and arthritis is not common; nevertheless, in one other patient who showed the sequence, the S.C.A.T. promptly reverted to positive when the arthritis relapsed after a long interval. Thus it seems unlikely that the patients in this study had been sero-positive at an earlier (unobserved) stage of their disease and were sero-negative but still active on the first presentation. It seems probable, therefore, from this study of thirteen patients who eventually became sero-positive, that some may have typical, active, and severe rheumatoid arthritis for many years, at least 15 in one instance, before sero-conversion occurs. With this evidence it is possible to conclude that the 23 patients who remained sero-negative at follow-up, and who had a typical distribution of arthritis, were examples of an incompletely developed rheumatoid arthritic process. However, it is intellectually unsatisfactory to imagine a forme fruste of a disease which is yet severe enough to be rapidly fatal, as in Case 4. Clearly we need to know more about what determines the appearance of the rheumatoid factor in the blood stream in patients with otherwise typical and severe rheumatoid arthritis.

The eight patients with atypical polyarthritis and a persistently negative S.C.A.T. are difficult to accept as having some form of rheumatoid arthritis as we ordinarily know it. They are not an homogenous group and if they do represent atypical forms of known polyarthritic disorders, might in five out of eight cases be better fitted in with disorders such as Reiter's disease or psoriatic arthropathy. Two patients at least (Cases 10 and 11) seem to be examples of an as yet undescribed polyarthritic disease or diseases, unless they are considered to have "periarthritis rhizomelique" (Forestier and Certonciny, 1953, 1958). Recognition of such 
cases is important, both from the point of view of prognosis of the individual, and of studies of prognosis generally in rheumatoid arthritis related to the S.C.A.T. Thus several observers have noted that patients with sero-negative "rheumatoid arthritis" have a better prognosis than those who are sero-positive (Duthie, Brown, Knox, and Thompson, 1957; De Forest, Mucci, and Boisvert, 1956; Otten and Westendorp Boerma, 1959). The inclusion of patients with sero-negative polyarthritis other than rheumatoid arthritis in such studies, might have contributed to this favourable impression. Nevertheless, the presence of a persistently negative S.C.A.T. is compatible with severe deformity or even with a fatal outcome in patients with a typical distribution of arthritis.

Similar considerations apply to studies of treatment in rheumatoid arthritis. The inclusion of sero-negative patients, destined to develop polyarthritic disorders other than rheumatoid arthritis, may introduce bias into therapeutic trials if distributed unequally between treatment groups, or at best will "dilute" any differences between treatment groups which may be due to the effects of treatment. Kellgren (1957) has written:

"In the small series studied in this trial (early rheumatoid arthritis treated with cortisone or aspirin), the prognosis of patients giving only negative results was much better than those giving only positive results, but there appeared to be no difference between those giving only positive results and those giving both positive and negative results in the test [S.C.A.T.]. Among the patients in whom the test was always negative, there were several with severe widespread polyarthritis and a high E.S.R. on entry to the trial, and such negative tests and good prognosis cannot be entirely explained in terms of trivial disease. In therapeutic trials, sheep cell agglutination tests should be performed regularly and patients giving only negative results studied separately."

It would seem wise to apply this principle to all reports of the effects of treatment, prognosis, or associated features of "rheumatoid arthritis", so that findings may be reproducible from centre to centre. One patient (Case 17), who was later to develop psoriasis, had been included in a large-scale therapeutic trial of cortisone compared with aspirin. He had been treated with cortisone and had done well. Retrospectively, it seems possible that this was because of the more favourable prognosis of psoriatic arthropathy rather than of the benefits of cortisone therapy. In retrospect also, there had been no firm way of differentiating his arthritis from that of rheumatoid arthritis, except the persistently negative S.C.A.T.
The history of the differentiation of the various forms of chronic polyarthritis dates from comparatively recent times. In a medical dictionary of 1825 , arthritis and gout are tautologous (Hooper, 1825). Garrod (1876) established a concept of rheumatoid arthritis which still embraced other diseases. The 20th century has seen first the firm separation of proliferative or osteo-arthritis from atrophic or rheumatoid arthritis, and later the separation of ankylosing spondylitis from rheumatoid arthritis. Reiter's disease has emerged (Harkness, 1950) and has since merged with the chronic variety of postvenereal arthritis to establish a separate entity. With the widespread use of the S.C.A.T. as a reference, there have separated from the body of rheumatoid arthritis the concepts of psoriatic arthropathy, and the arthropathies of ulcerative colitis and erythema nodosum. Behçet's and Bazin's diseases, when they affect the joints, are now seldom thought to be varieties of rheumatoid arthritis. Two conditions appearing amongst the non-rheumatoid disorders which were discovered in this follow-up study (namely the aortitis associated with spondylitis, and reticulohistiocytosis) had not been fully characterized when the relevant patients in this study had first been observed. Thus it does not seem improbable that some of the polyarthritic disorders described in this paper, which are unlike typical rheumatoid arthritis, and have been associated wit a persistently negative S.C.A.T., are examples of hitherto undescribed diseases. Further study has disclosed two further examples of the "middle-agedfemale, severe-but-recovering, sero-negative, centraland-large-joint, polyarthritis"' (see Cases 10 and 11), but clearly "four swallows do not make a summer" and more case reports are needed. Here, as in the estimation of other polyarthritic disorders, the S.C.A.T. will remain the touchstone of diagnosis.

\section{Summary}

61 out of 63 in-patients with severe, active polyarthritis, associated with a persistently negative sheep cell agglutination test (S.C.A.T.) for rheumatoid arthritis are reviewed. The average duration of follow-up was $5 \cdot 4$ years.

Of the 61 patients reviewed, twelve were found at follow-up to have developed a positive S.C.A.T. All but two of these had a distribution of arthritis typical of rheumatoid arthritis and six developed subcutaneous nodules. The course of their arthritis was not different from that seen in 23 patients in whom the arthritis was also typical but in whom the S.C.A.T. remained negative. Both mild and severe end-results were seen. A persistently negative 
S.C.A.T. was compatible with typical rheumatoid arthritis of progressive course and fatal outcome.

Eleven patients had proven or probable diseases other than rheumatoid arthritis, these included gout, generalized osteo-arthritis, psoriatic arthropathy, reticulohistiocytosis, Takayushu's disease, Reiter's disease, and myelomatosis.

Eight patients showed a persistently negative S.C.A.T. and an atypical arthritis. The disease in these patients conformed to no accepted nosology and may have been examples of undescribed polyarthritic disorders. The evidence for this seemed strongest in two middle-aged females with severe and prolonged central and spinal polyarthritis associated with marked constitutional disease, proceeding to complete remission.

A reproducible diagnosis of rheumatoid arthritis requires a positive specific sheep cell agglutination test as well as clinical evidence of polyarthritis. In clinical studies of this disease the results of agglutina. tion tests should be stated, and patients with persis. tently negative tests excluded or separately assessed.

I am indebted to various clinical colleagues, particularly Professor J. H. Kellgren and Dr. J. Sharp, for initial observations on these patients, and to Dr. J. Ball for the serological studies on which the selection of patients was based.

\section{REFERENCES}

Ask-Upmark, E. (1954). Acta med. scand., 149, 161.

and Fajers, C-M. (1956). Ibid., 155, 275.

Ball, J. (1950). Lancet, 2, 520.

Brown, H. (1945). J. biol. Chem., 158, 601.

Bywaters, E. G. L. (1950). Brit. Heart J., 12, 101.

Carter, M. E., and Scott, F. E. T. (1959). Ann. rheum. Dis., 18, 65.

Clark, W. S., and Bauer, W. (1948). Ibid., 7, 39.

De Forest, G. K.. Mucci, M. B., and Boisvert, P. L. (1956). Amer. J. Med., $21,897$.

Duthie, J. J. R., Brown, P. E., Knox, J. D. E., and Thompson, M. (1957). Ann. rheum. Dis., 16, 411.

Forestier, J., and Certonciny, A.'(1953). Rev. Rhum., 20, 854.

-, (1958). Sem. Hôp. Paris, 34, 3220.

Garrod, A. B. (1876). "The Nature and Treatment of Gout and Rheumatic Gout", 3rd ed., cited by A. E. Garrod (1890) in "A Treatise on Rheumatism and Rheumatoid Arthritis", p. 270. Griffin, London.

Graham, D. C., and Smythe, H. A. (1958). Bull. rheum. Dis., 9, 171 .

Hall, A. P., Mednis, A. D., and Bayles, T. B. (1958). New Engl. J. Med., 258, 731

Harkness, A. H. (1950). "Non-gonococcal Urethritis", p. 99. Livingstone, Edinburgh.

Hooper, R. (1825). "Lexicon Medicum, or Medical Dictionary", 5 th ed., p. 564 . Longmans, London.

Jacqueline, F.. Podliachouk, L., and Eyquem, A. (1956). Rev. franc. Études clin. biol., 1, 1092.

Kellgren, J. H. (1957). Brit. med. J., 1, 850.

- and Ball, J. (1959). Ibid., 1, 523.

and Lawrence, J. S. (1956). Ann, rheum. Dis., 15, 1.

and Moore, R. (1952). Brit. med. J., 1.181

Ludwig, A. O., Bennett, G. A., and Bauer, W. (1938). Ann. intern. Med., 1i, 1248.

Mason, R. M., Murray, R. S., Oates, J. K., and Young, A. C. (1959). J. Bone Jt Surg., $41 \mathrm{~B}, 137$.

Mote, J. R., and Jones, T. D. (1941). J. Immunol., 41, 35.

Otten, H. A., and Westendorp Boerma, F. (1959). Ann. rheum. Dis., $18,24$.

Ropes, M. W., Bennett. G. A., Cobb, S., Jacox, R., and Jessar, R. A. (1956). Bull. rheum. Dis., 7, 121 .

Sharp, J. (1957). Brit. med. J., 1, 975.

Takayushu, M. (1908). Acta Soc. Ophthal. jap., 12, 554.

Takayushu, M. (1908). Acta Soc. ophthal. jap., 12, 554.
Warin, R. P., Evans, C. D., Hewitt, M., Taylor, A. L., Price, C. H. G. and Middlemiss, J.'H. (1957). Brit. med. J., 1, 1387.
Weissenbach, R. J. (1938). Arch. Derm. Syph. Clin. Hôp. Saint Louis, 10, 13

Wright, V. (1957). Brit. J. Dermatol., 69, 1.

(1959). Amer. J. Med., 27, 454.

Ziff, M. (1957). J. chron. Dis., 5, 644.

, Brown, P., Lospalluto, J., Badin, J., and McEwen, C. (1956). Amer. J. Med., $20,500$.

\section{"Arthrite rhumatismale" avec une réaction sérologique négative \\ RÉSUMÉ}

On passe en revue 61 cas de polyarthrite évolutive grave, associée à une réaction d'agglutination des globules de mouton (sheep cell agglutination test = S.C.A.T.) constamment négative. Le temps moyen d'observation fut de 5,4 ans.

Sur ces 61 cas, douze d'entre eux développèrent au cours de la période d'observation une S.C.A.T. positive. Chez tous ces malades, sauf deux, la distribution de l'arthrite fut typique d'arthrite rhumatismale et six d'entre eux accusèrent des nodules souscutanés. L'évolution de leur arthrite ne se distinguait en rien de celle des 23 malades atteints d'une arthrite pas moins typique, mais chez qui la S.C.A.T. avait demeuré négative. On vit des résultats finaux graves et on en vit des benins. Une S.C.A.T. toujours négative fut compatible avec une arthrite rhumatismale typique d'un cours progressif menant à la mort.

Dans onze cas, des maladies autres que l'arthrite rhumatismale furent prouvées ou probables; parmi elles on trouva la goutte, l'ostéoarthrite généralisée, l'arthropathie psoriasique, la réticulohistiocytose, la maladie de Takayushu, la maladie de Reiter et la myelomatose.

Huit malades présentèrent une S.C.A.T. négative persistante avec une arthrite atypique. Ici la maladie ne correspondait à aucune entité nosologique et il pourrait s'y agir de désordres polyarthritiques non décrits auparavant. Ce groupe est caractérisé particulièrement par deux femmes d'un âge moyen, atteintes d'une polyarthrite centrale et vertébrale, grave et prolongée, associée à une maladie diathésique marquée, avec une évolution vers la rémission complète.

Un diagnostic ferme d'arthrite rhumatismale demande une S.C.A.T. spécifique positive en même temps que des signes de polyarthrite. Quand on étudie la pathologie de cette maladie, les résultats des réactions d'agglutination doivent être exprimés et les malades avec une réaction toujours négative doivent être exclus ou bien appréciés séparément.

\section{"Artritis reumatoide" con reacción serológica negativa}

\section{SUMARIO}

Se relatan 61 casos de poliartritis evolutiva grave, asociada con persistente negatividad de la reacción de aglutinación de los eritrocitos de carnero (sheep cell agglutination test $=$ S.C.A.T.). El tiempo medio de observación fué de 5,4 años.

De estos 61 casos, doce desarrollaron durante el período de observación una S.C.A.T. positiva. En todos estos enfermos, excepto dos, la distribución de la artritis fué típica de artritis reumatoide y seis de ellos desarrollaron nódulos subcutáneos. La evolución de su artritis no presentó ninguna diferencia con la de 23 enfermos em los cuales la artritis fué también típica, pero en quienes la S.C.A.T. permaneció negativa. Se vieron tanto graves como leves resultados finales. Una S.C.A.T. siempre negativa fué compatible con una 
artritis reumatoide típica de curso progresivo y terminación fatal.

En once casos enfermedades otras que la artritis reumatoide fueron comprobadas o probables; estas incluían gota, osteoartritis generalizada, artropatía psoriásica, reticulohistiocitosis, enfermedad de Takayushu, enfermedad de Reiter y mielomatosis.

Ocho enfermos presentaron una S.C.A.T. negativa persistente y artritis atípica. La enfermedad en estos pacientes no se adaptaba a ninguna determinada nosología y pueden haber sido ejemplos de desórdenes poliarticulares no descritos como entidad patológica.
Los casos más evidentes de este grupo están represen-市 tados por dos enfermas de edad media con grave y prolongada poliartritis central y vertebral, asociada con marcado defecto constitucional, que evolucionaron hacia $-\bar{s}$ la completa remisión.

Un diagnóstico reproducible de artritis reumatoide requiere específica reacción de aglutinación de los eritrocitos de carnero positiva a la vez que evidencia드 clínica de poliartritis. En los estudios clínicos sobreo esta enfermedad, los resultados de dicha reacción $\overline{\bar{S}}$ deberían ser expresados y los enfermos con persistente reacción negativa excluidos o apreciados separadamente. $\varrho$ 